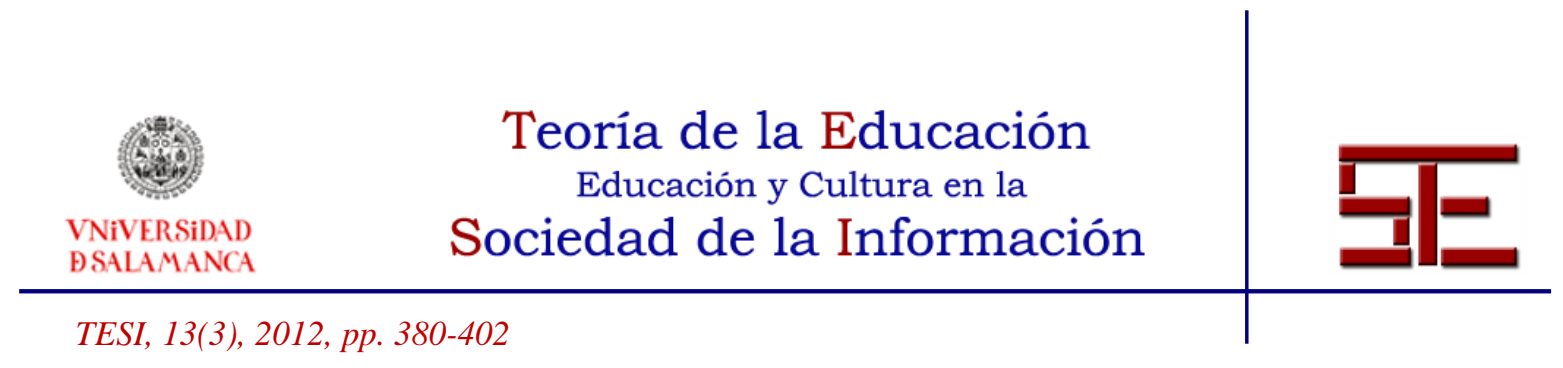

\title{
DESARROLLO DE HABILIDADES ESCRITURALES APOYADO CON TECNOLOGÍA MÓVIL ${ }^{1}$
}

Resumen: Hoy en día el uso de tecnología móvil ha impactado en la enseñanza de una segunda lengua ya que en los procesos de aprendizaje se está implementando el uso de dispositivos móviles con el fin de apoyar las diferentes habilidades de la lengua, particularmente la oral. Sin embargo, son pocos los estudios que apuntan a mejorar la habilidad de escribir. Este artículo describe un estudio de corte cuantitativo realizado para determinar el efecto del uso de recursos académicos y no académicos en dispositivos móviles, en el desarrollo de habilidades escriturales en inglés, de un grupo de estudiantes universitarios de primer ingreso. Esta investigación se fundamenta en la perspectiva Sistémico-Funcional (Halliday) específicamente en la teoría de géneros de Martin \& Rose (2007) y en el enfoque de aprendizaje de lenguas asistido por tecnología móvil. Se evaluaron las habilidades escriturales en los textos producidos por los estudiantes en torno a la estructura genérica del texto, cohesión, aspectos mecánicos y gramaticales, antes y después de la experiencia con tecnología móvil. Los resultados revelan mejoras en las habilidades escriturales después del uso de los recursos, correlacionándose significativamente con la frecuencia de consulta de los de tipo académico.

Palabras clave: aprendizaje de segunda lengua; habilidades escriturales; género narrativo; recursos; aprendizaje móvil.

\footnotetext{
${ }^{1}$ Proyecto financiado por la Vicerrectoría Académica y la Dirección de Investigaciones y Proyectos de la Universidad del Norte en la VIII Convocatoria Interna para proyectos de Investigación y Desarrollo en el Marco de la Estrategia de Fortalecimiento de Grupos y Centros de Investigación Uninorte- 2010.
}

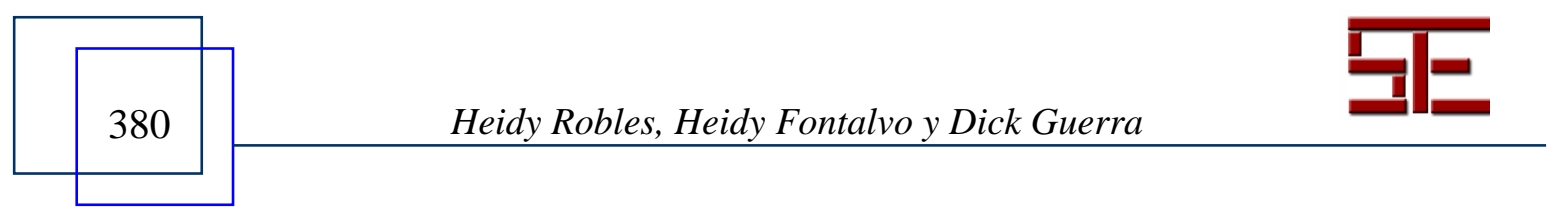




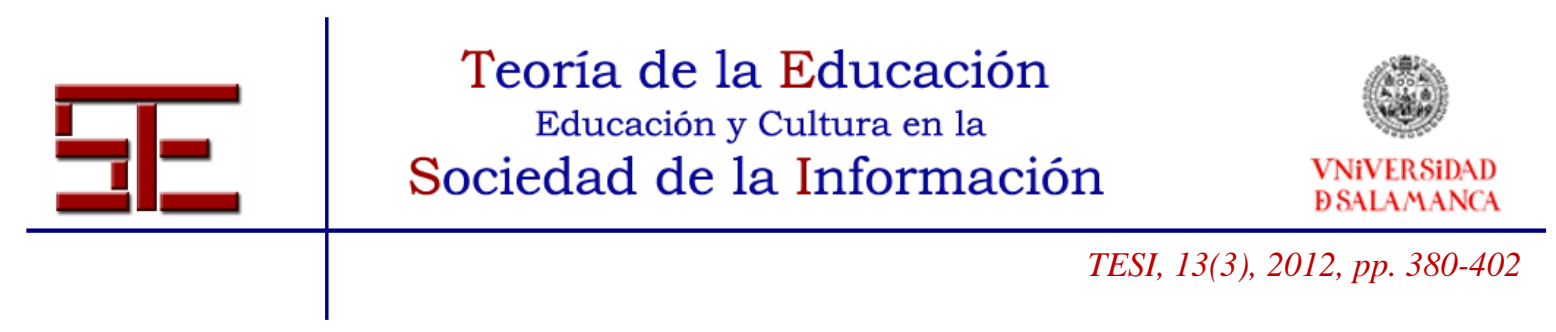

\title{
DEVELOPMENT OF WRITING SKILLS BASED ON MOBILE LEARNING
}

\begin{abstract}
Nowadays the use of the mobile learning has an impact in the teaching of a second language since it is incorporating in the processes of learning in order to support the different abilities of the language particularly the oral skills. However, there are few studies that deal with improving writing skills through mobile devices. This article describes a quantitative study to test the effect of using academic and nonacademic resources in mobile devices to develop writing skills in English in a group of freshmen university students. The theoretical framework used in this research examines the Systemic Functional Linguistics (Halliday) specifically, the genre theory of Martin \& Rose (2007) and the approach of language learning assisted by mobile devices (MALL). The student's writing skills were evaluated in the texts produced by them according to the generic structure of the text, cohesion, accuracy and mechanics aspects (spelling/capitalization and punctuation) before and after the m-learning experience. The data show a better performance in the student's writing skills after using the resources; the results correlated significantly with the number of times of academic resources reviewed by students.
\end{abstract}

Keywords: Second language; learning; writing skills; narrative genre; resources; m- learning.

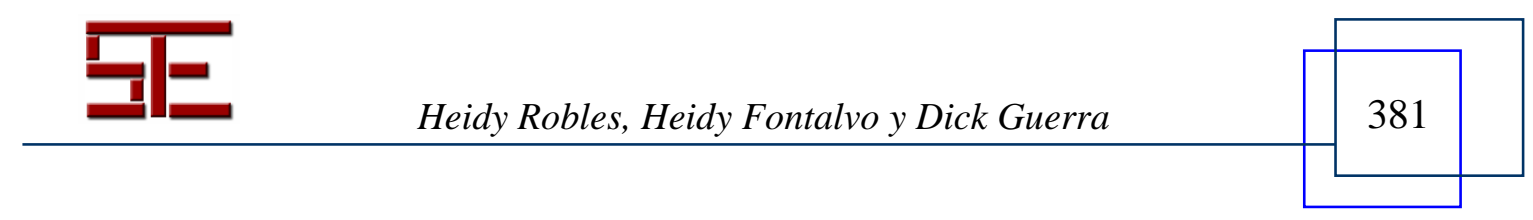




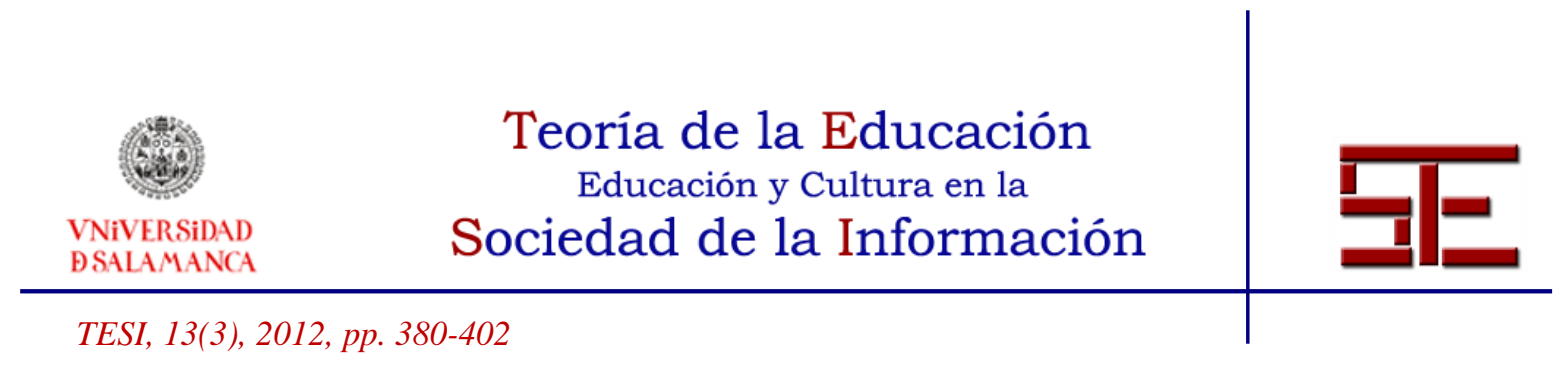

\section{DESARROLLO DE HABILIDADES ESCRITURALES APOYADO CON TECNOLOGÍA MÓVIL}

Fecha de recepción: 20/09/2011; fecha de aceptación: 18/09/2012; fecha de publicación: 30/11/2012

Heidy Robles

hrobles@uninorte.edu.co

Universidad del Norte. Colombia

Heidy Fontalvo

hfontalvo@uninorte.edu.co

Universidad del Norte. Colombia

Dick Guerra

dickbasic@gmail.com

Universidad del Norte. Colombia

\section{INTRODUCCIÓN}

En el campo de la enseñanza de idiomas, desde los años setenta se comenzó a hablar de tecnología en el aula de clase como un instrumento que facilita la enseñanza de una segunda lengua (Hanson, 2000); se han incorporado desde entonces diversas tecnologías en el desarrollo de las diferentes habilidades del lenguaje. Estudios como los de Stockwell (2007) indican que el uso de tecnologías para el desarrollo de habilidades en el lenguaje es muy amplio y que han abordado por ejemplo las habilidades básicas de lectura, escritura, escucha y habla. Específicamente en el desarrollo de la escritura, las tecnologías usadas incluyen actividades en línea, software para el análisis de textos (Corpora \& Concordancing), procesadores de textos y diccionarios. De acuerdo a esta revisión no se encuentran estudios que incorporen tecnología móvil para el desarrollo de esta habilidad pero sí sobre vocabulario. En todo caso, la implementación de dispositivos de información en las aulas define nuevos enfoques y tendencias en el ámbito denominado MALL (Mobile Assisted Language Learning), el cual en Asia ha registrado el mayor cuerpo de investigación vigente, probablemente debido a la gran penetración de estos dispositivos en este continente (Mork, 2009).

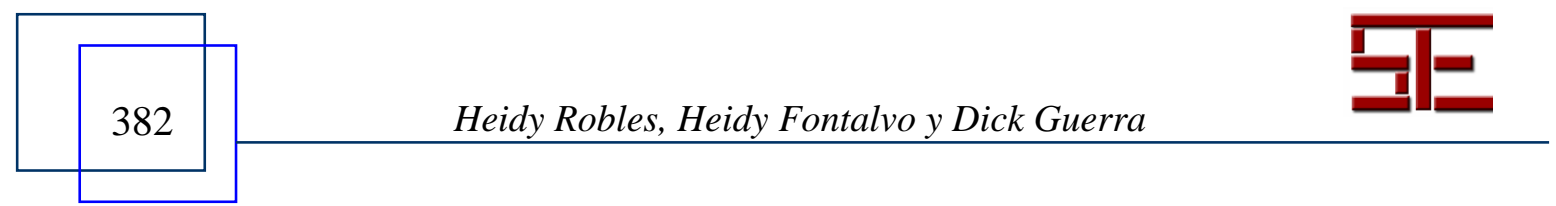




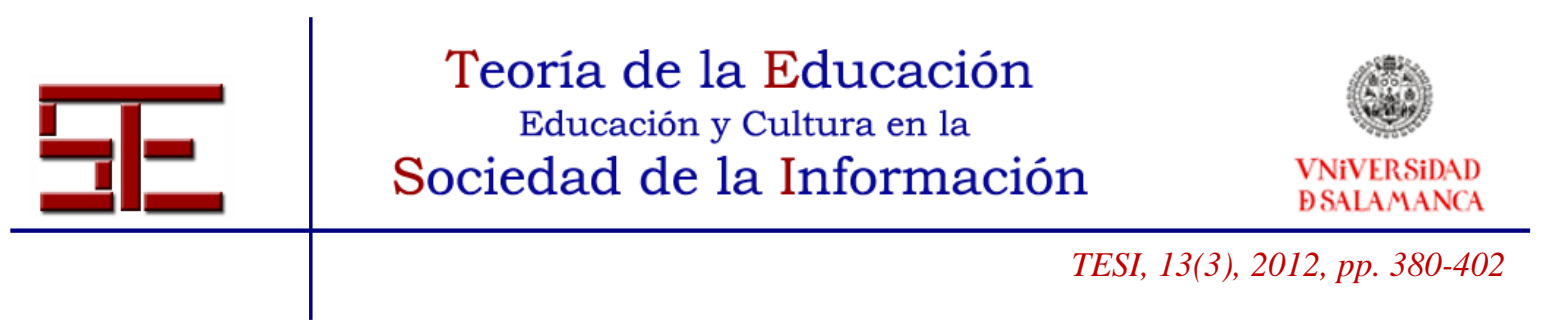

\section{REFERENTES TEÓRICOS}

\subsection{Escribir en una segunda lengua}

Escribir es considerada una de las habilidades más complejas de desarrollar en una segunda lengua (Richards \& Renandya, 2002; Zheng, 1999). Grabowski (citado por Cushing, 2002) define la habilidad de escribir comparada con la habilidad oral como un sistema estandarizado adquirido a través de una rigurosa instrucción. Nunan (1999, 271) también la considera como un enorme reto: "Producir un texto coherente, fluido y extenso es probablemente lo más difícil de hacer en un idioma". Cushing (2002) y Richards \& Renandya (2002) señalan que el escribir en una segunda lengua puede tener ciertos obstáculos relacionados más con la forma que con el contenido, ya que si la suficiencia del lenguaje es limitada o débil las dificultades para escribir aumentan.

Entre las diferentes perspectivas pedagógicas para abordar la habilidad escritural y la producción de textos en una segunda lengua se encuentra el enfoque de género, cuyos fundamentos teóricos apoyan este estudio específicamente, en los conceptos de Martin y Rose (2007) y Rose (2008). Estos autores definen género como diferentes tipos de textos que representan contextos sociales, los cuales comparten una serie de características, por ejemplo, ciertas etapas y fases dentro del texto que son necesarias para lograr un propósito. Algunas veces, estos textos también presentan rasgos gramaticales y lexicales similares. Ser capaz de identificar un género cuando se lee ayuda a entenderlo y evaluarlo, ya que se conoce el tipo de información que se espera o que falta en el mismo, así mismo familiarizarse con las características de un género es útil al producir textos de un mismo género (Rose, 2008).

Con respecto a la eficacia de este enfoque para mejorar la escritura en una segunda lengua asistido por tecnología, Martínez y Tabuenca (2008) adoptaron la teoría de género integrado a un 'software' para corregir textos, con el fin de que los estudiantes tomaran conciencia de la relación entre la estructura y forma de los textos. Los resultados demuestran una notable mejora en las habilidades de escritura en general de los estudiantes. Los textos fueron mejor estructurados, con buenos inicios y finales. También hubo un aumento de buenas ilustraciones y un uso mucho más frecuente de las transiciones. Estas autoras afirman que el hacer explícitos los géneros y mostrar cómo escribir ayuda a los estudiantes a ser conscientes de cómo el conocimiento se estructura en diferentes géneros escritos. Los resultados de este estudio demuestran que la combinación de las nuevas tecnologías en el aula y la teoría de género han servido para que los estudiantes aumenten su capacidad de escritura en una segunda lengua.

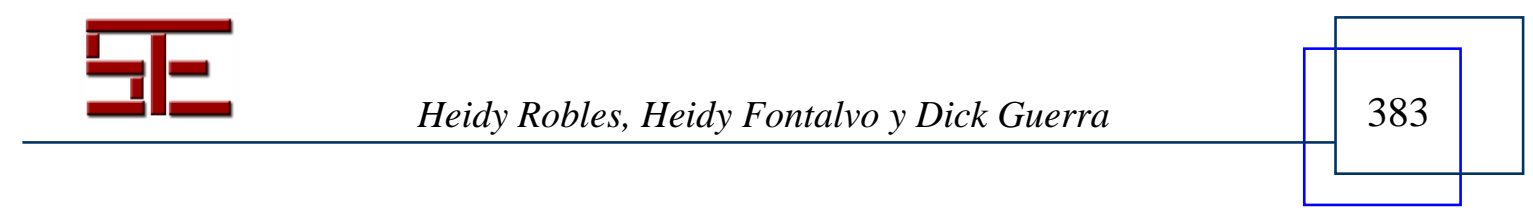




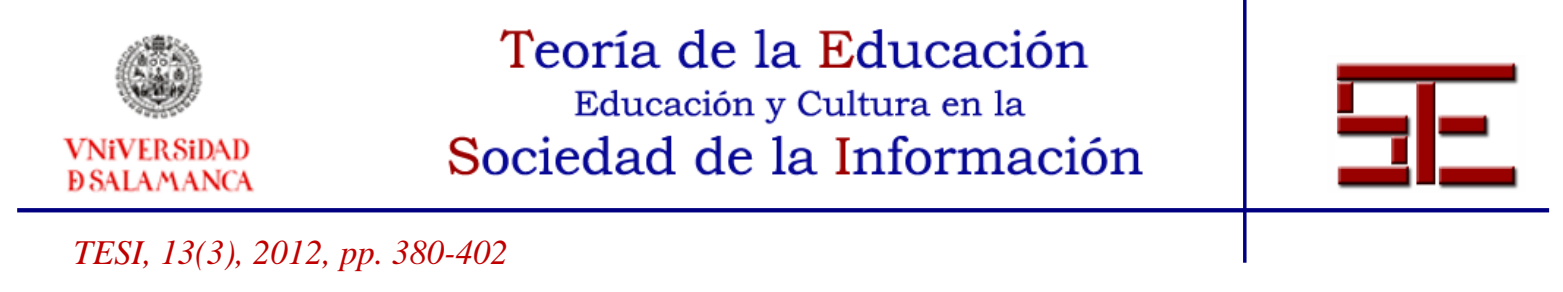

Más adelante, un estudio realizado por Chaisiri (2010) reveló resultados satisfactorios en la habilidad escritural y actitudes de los estudiantes en una clase de escritura basada en el enfoque de género. El estudio concluyó que este enfoque tiene el potencial para resolver problemas para la enseñanza y aprendizaje de la escritura del inglés. Específicamente en la producción de recuentos y argumentaciones, Chaisiri (2010) encontró mejoras significativas entre los textos previos y los posteriores a la intervención de las lecciones de clase basadas en el enfoque de género: la estructura, longitud, características del lenguaje, uso de conjunciones y conectores fueron mejorados significativamente.

Otros aspectos que se deben abordar la producción de textos independiente del enfoque son la coherencia y la cohesión. Díaz $(2009,28)$ define la coherencia como "una propiedad semántica y pragmática del texto, que se refiere a dos tipos de relaciones lógicas: la existente entre los conceptos de la oración y las existentes entre cada oración". Es decir, que un texto es coherente cuando existe una armonía lógica en los elementos que conforman el texto y son significativos al lector. En cuanto a cohesión, Díaz (2009) se refiere a las conexiones morfosintácticas que permiten enlazar una cláusula, oración o párrafo con algún otro elemento mencionado previamente. Además, en la evaluación de las habilidades escriturales en una segunda lengua, Brown (2007) propone tener presentes categorías o criterios tales como contenido, organización, sintaxis, vocabulario y aspectos mecánicos relacionados con la ortografía, puntuación y uso apropiado de mayúsculas. Igualmente, Nunan (1999) sugiere criterios similares y los agrupa en tres grandes conceptos: precisión (accuracy), aspectos de la lengua y organización en la estructura.

Este estudio adopta el enfoque de género más los criterios de Brown y Nunan para la evaluación de habilidades escriturales apoyado con tecnología móvil.

\subsection{Desarrollar habilidades en una segunda lengua con tecnología móvil}

Con respecto a la adquisición de vocabulario, Kiernan y Aizawa (2004) mostraron que hubo una ganancia del mismo en un grupo de estudiantes al usar teléfonos móviles luego de hablar y de usar el correo electrónico. En esa misma línea, Lu (2008) empleó mensajes de texto (SMS) para apoyar el aprendizaje de vocabulario y encontró que los estudiantes adquirieron más vocabulario al consultar los SMS que estudiando sólo el material impreso. Igualmente, Cavus e Ibrahim (2009) encontraron mejoras significativas en el vocabulario cuando compararon los rendimientos iniciales y finales

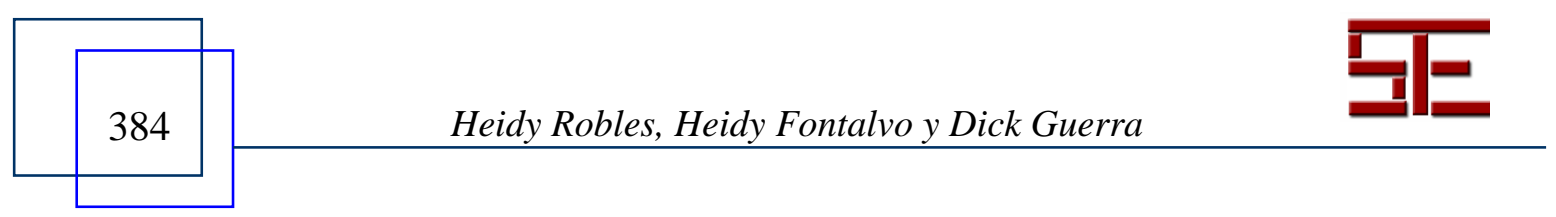




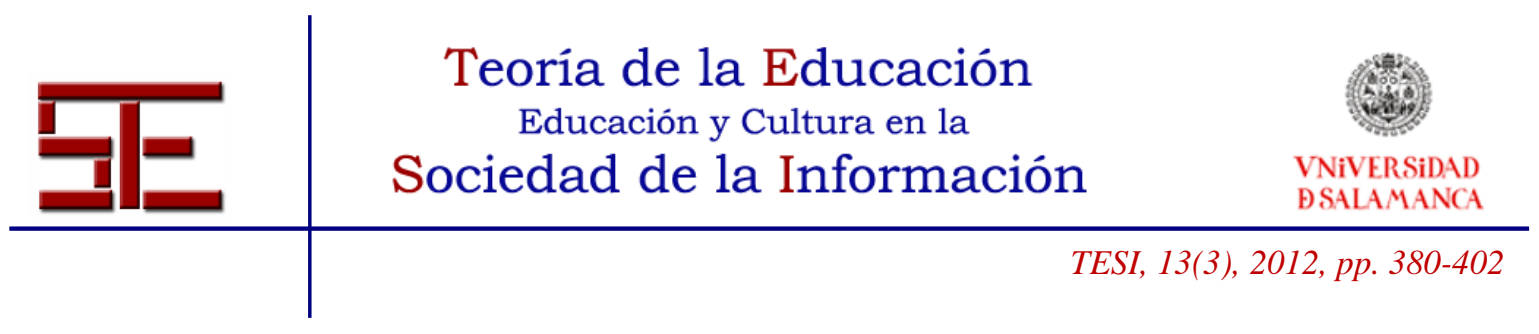

de un grupo de estudiantes de computación que usaron una aplicación de SMS para revisar significado de vocablos.

En cuanto a la habilidad escritural, Chinnery (2006) indicó que una de las nuevas tecnologías con potencial aplicación en el aprendizaje de idiomas es el moblogging (móvil + blog), el cual consiste en publicar palabras en un sitio web por medio del dispositivo. Este autor manifiesta el impacto positivo de esta aplicación para la enseñanza del inglés como una segunda lengua en el Japón y que ha sido utilizado para elaborar composiciones obteniéndose resultados satisfactorios en el desarrollo de la escritura. En este mismo país, un estudio realizado por Gromik (2008) reveló que los estudiantes dedicaban entre dos y cuatro horas por semana a escuchar o ver recursos en ingles en sus 'i Pods', particularmente 'podcast' de video de su interés seleccionados por ellos mismos, y que utilizaban los dispositivos móviles fuera del aula de clase para aprender en su tiempo de estudio independiente, desarrollando una mayor conciencia de uso del lenguaje.

En esta misma línea, la investigación de Sandberg, Maris y De Geus (2011) muestra que los estudiantes que utilizaron dispositivos móviles tanto en la clase como en la casa tuvieron un mejor desempeño que aquellos estudiantes que solo lo implementaron en la clase. Los resultados indicaron que los aprendices estaban motivados al utilizar las aplicaciones de 'm-learning' en su tiempo libre. Estos autores concluyeron que el aprendizaje formal puede ser aumentado en ambientes informales, es decir, fuera de la institución educativa. Resultados similares muestra el estudio de De Jong, Specht y Koper (2010), quienes encontraron ganancia de conocimiento del idioma en un grupo de estudiantes al momento de utilizar un material educativo contextualizado en dispositivos móviles.

Particularmente sobre el tema de 'podcasting' (nombre del proceso de diseño, producción e implementación de 'podcast') McCarthy (2005) señala que los 'podcast' (archivos de audio y/o video difundidos por Internet) han facilitado el aprendizaje del inglés como lengua extranjera. Esto confirma lo planteado por autores como Vallance y Shibata (2008), quienes presentaron el tema de producción de párrafos en 'podcast' en una clase de estrategias de habilidades comunicativas. La ayuda de este material consistió en reforzar los componentes de un párrafo y para que los estudiantes realizaran una producción oral, también a través de un 'podcast'. Los resultados muestran un incremento del $15 \%$ y $10 \%$ en la capacidad de reconocimiento y recuerdo de la información obtenida usando los dispositivos en dos grupos de estudiantes. De

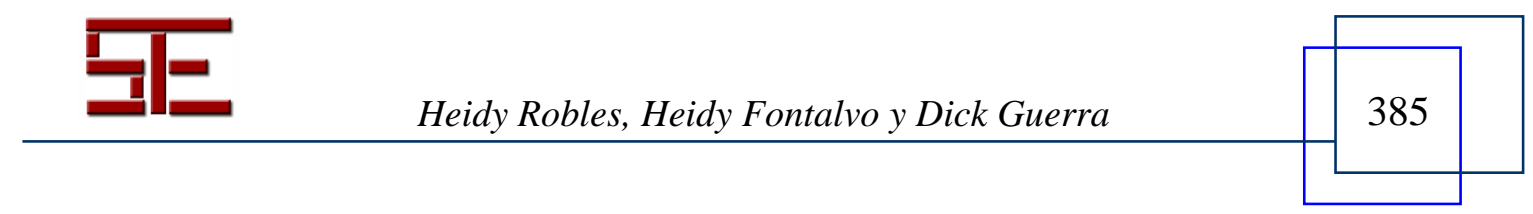




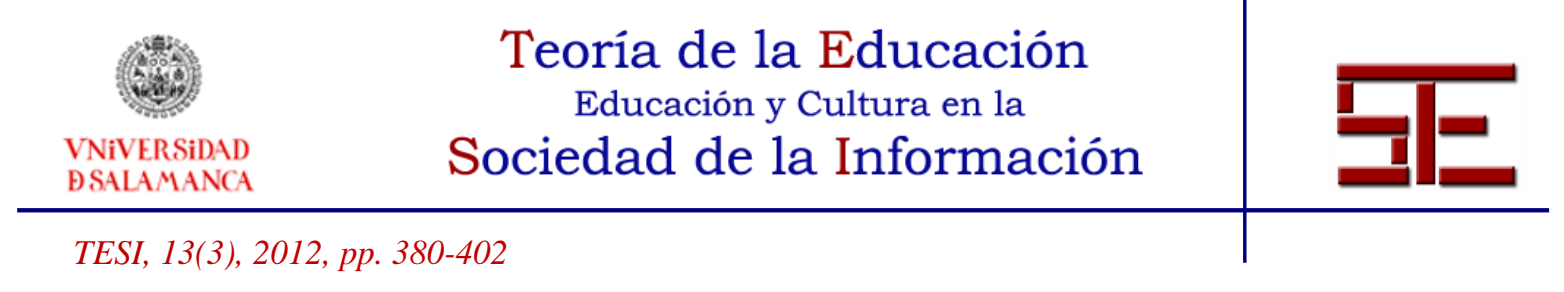

acuerdo a estos autores, el uso de los dispositivos móviles (tanto para presentar el contenido como para la ejecución de la tarea) tuvo un impacto positivo en la retención de información. Además, indican que antes de introducir a los estudiantes en el 'podcasting' es fundamental que el instructor prepare el objetivo de la tarea, determine un enfoque específico de la habilidad a desarrollar, una clara visión del resultado esperado y una forma de evaluar.

Recientemente Lomicka y Lord (2011) abordaron los propósitos con que los docentes de idiomas han implementado el 'podcasting', encontrando que un $41 \%$ del uso dado a los 'podcast' va dirigido al desarrollo de habilidades de escucha, mientras que otro $35 \%$ comprende mejor el habla y la pronunciación. Solo un 3\% de uso va dirigido a desarrollar habilidades escriturales y un porcentaje similar al vocabulario.

\subsection{Recursos de aprendizaje para dispositivos móviles}

El objetivo del 'm-learning' es el de incorporar las tecnologías móviles al servicio del aprendizaje; ello implica que, hasta cierto grado, los recursos deben ser reelaborados en un formato asequible desde dispositivos móviles. Taylor (2007) anota que no todos los contenidos de aprendizaje sirven para el aprendizaje móvil y que se deben escoger cuidadosamente las herramientas. Una parte importante de los contenidos de un programa deberá trabajarse de manera habitual y solo aquellos recursos que no requieran constante retroalimentación, que sean tan breves y livianos como para ser revisados en corto tiempo y ser almacenados en la memoria de un dispositivo portátil, podrán usarse para este propósito. Además, deben ser descargados o enviados fácilmente y ser gráficamente pequeños para ser visualizados en la pantalla de un 'Smartphone' (Looi; Seow; Zhang; So; Chen \& Wong, 2010).

Con respecto a la visualización de los recursos, los hallazgos de Chen, Hsieh y Kinshuk (2008) muestran que cuando se proveen recursos de aprendizaje con anotaciones pictóricas en un ambiente de aprendizaje móvil de una lengua, se favorece a los estudiantes con menor habilidad verbal y mayor habilidad visual. Los resultados también indican que el proveer de mucha información en un recursos para dispositivos móviles puede ocasionar una alta carga cognitiva, que produce irritabilidad y falta de concentración.

Con respecto a los 'podcast' los estudios de Parson, Reddy, Wood y Senior. (2009), como también los de Jarvis \& Dickie (2010) muestran que los estudiantes y

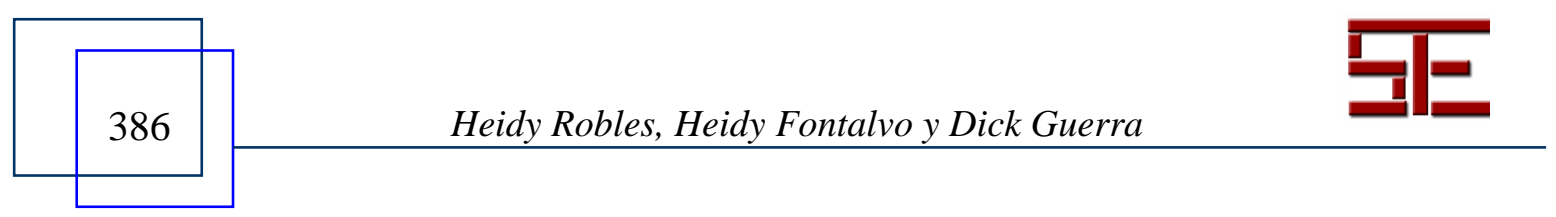




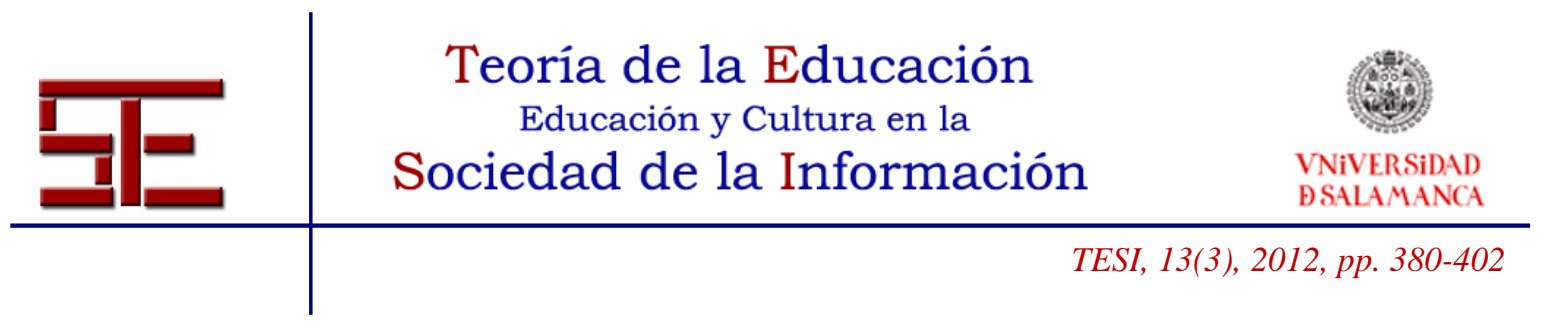

docentes los perciben como recursos educativos que sirven para apoyar los procesos instruccionales y no como elementos que por sí mismos pueden llevar al aprendizaje. Shih, Chuang y Hwang (2010) advierten que los resultados de aprendizaje pueden ser desfavorables si no se emplean estrategias de aprendizaje o herramientas adecuadas al momento de incorporar recursos y el m-learning. Gromik (2008) por su parte indica que el servicio de 'iTunes' y la tecnología de los 'iPod' proporcionan a los aprendices acceso a recursos que son auténticos, libres, que fomentan que los estudiantes piensen acerca del contenido que acceden, les proporciona actividad continua, consolidan sus conocimientos previos del idioma que están aprendiendo, se exponen a nuevo léxico y/o desarrollan un interés en aprender más acerca de un tema particular de su preferencia. Por lo tanto, a través de la tecnología móvil y la motivación que esta puede incitar, se puede desarrollar el aprendizaje de idiomas.

A partir de los referentes demarcados en la investigación en torno al aprendizaje de lenguas mediado por tecnología, este estudio busca determinar si el uso de recursos en dispositivos móviles puede favorecer el desarrollo de habilidades escriturales en una segunda lengua (inglés para hispano-hablantes).

\section{METODOLOGÍA}

\subsection{Diseño, muestra e instrumentos}

Se escogió un diseño cuasi-experimental de pretest y postest con un solo grupo, con el fin de hacer un seguimiento del mismo y de observar el nivel en la variable dependiente antes del estímulo. El grupo de participantes estuvo conformado por estudiantes de primer semestre entre 18 y 21 años, mixtos en género y habilidades, residentes en un área metropolitana, que cursaron la asignatura "Narrativa" en inglés, la cual está orientada al desarrollo de habilidades orales y escriturales. La muestra estuvo conformada por 23 estudiantes que desearon participar voluntariamente en la investigación. Se diseñó una rúbrica para evaluar el desarrollo de las habilidades escriturales de los estudiantes en escritos de género narrativo de acuerdo a los siguientes criterios: 1) género, 2) cohesión, 3) aspectos gramaticales (coherencia) y 4) aspectos mecánicos (Anexo 1). La rúbrica fue sometida a validación de contenido por jueces expertos en términos de: pertinencia, claridad, precisión, lenguaje y metodología. En cuanto al registro de la frecuencia de consulta de los recursos en los dispositivos móviles, se diseñó una tabla de registro y se revisó cada equipo con el software 'i Tunes' y 'Podtomac'.

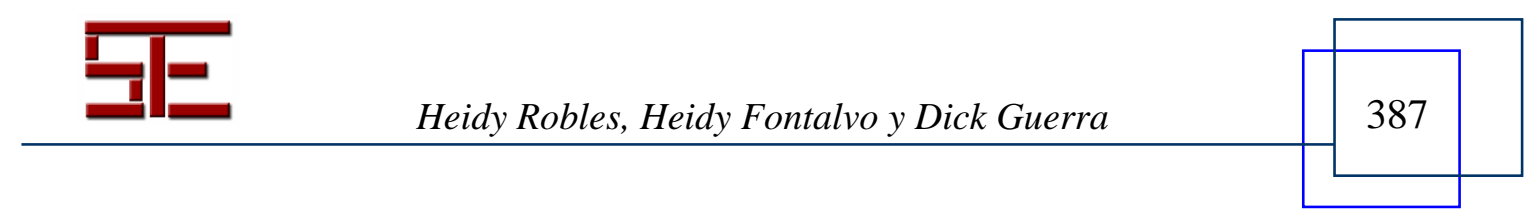




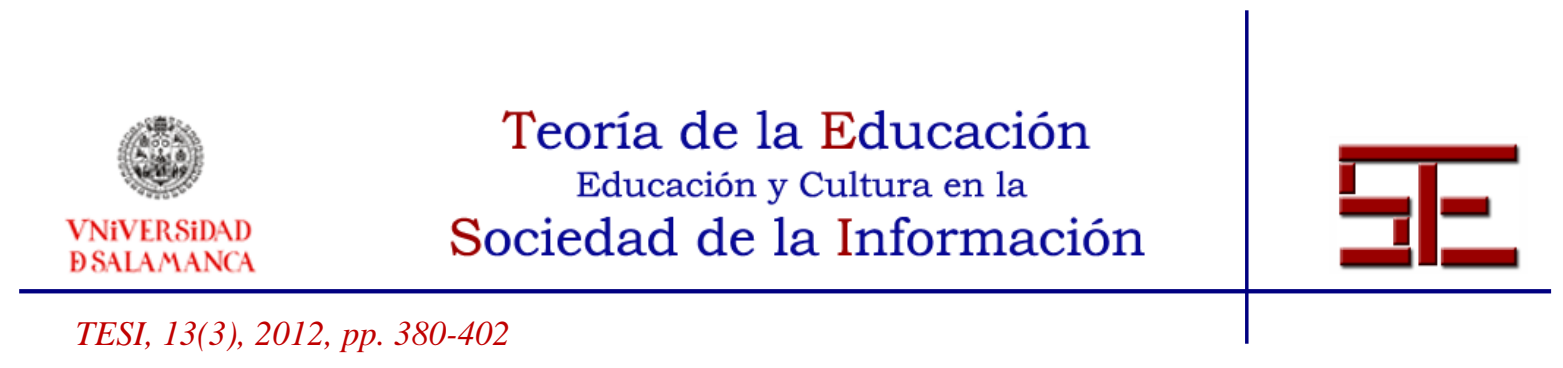

\subsection{Procedimiento}

La experiencia con dispositivos móviles se llevó a cabo durante cinco semanas, periodo escogido con el fin de evitar que otros acontecimientos generaran cambios, además del tratamiento experimental. Inicialmente los estudiantes participaron en una sesión de sensibilización sobre aprendizaje con tecnología móvil. A cada estudiante le fue asignado un dispositivo móvil y fueron instruidos sobre el procedimiento de préstamo, cuidado, descarga y reproducción de recursos. Luego, cada estudiante realizó la producción de los textos escritos (pretest) en donde se evaluaron las habilidades escriturales previas al uso de los dispositivos siguiendo la rúbrica. Cada semana los estudiantes consultaban libremente recursos en sus dispositivos móviles de diversa índole: 1. Recursos en inglés, entre ellos 'podcast' diseñados por la profesora acerca de la estructura de los tipos de texto del género narrativo, páginas web, traductores, videos, aplicaciones/juegos, música y la página web del curso en WebCT, y 2. recursos varios, de uso personal y de entretenimiento, tales como redes sociales, correo electrónico, videos, páginas web, entre otros. Al finalizar cada semana se revisaban los dispositivos para registrar la frecuencia de consulta de los recursos por parte de cada estudiante. En último lugar, los estudiantes realizaron una producción escrita final (postest) de acuerdo a los mismos criterios y condiciones de la evaluación inicial (pretest).

\section{RESULTADOS}

Se analizaron las habilidades escriturales de un grupo de estudiantes $(\mathrm{N}=23)$ antes y después de la consulta de recursos en dispositivos móviles. Los resultados indican que hubo una diferencia significativa en las habilidades escriturales después de la experiencia de uso de los dispositivos móviles. Como se muestra en la Tabla 1, el promedio de los resultados en el pretest de habilidades escriturales fue de 2.79 mientras que el promedio de los resultados del postest incrementó a 3,88.

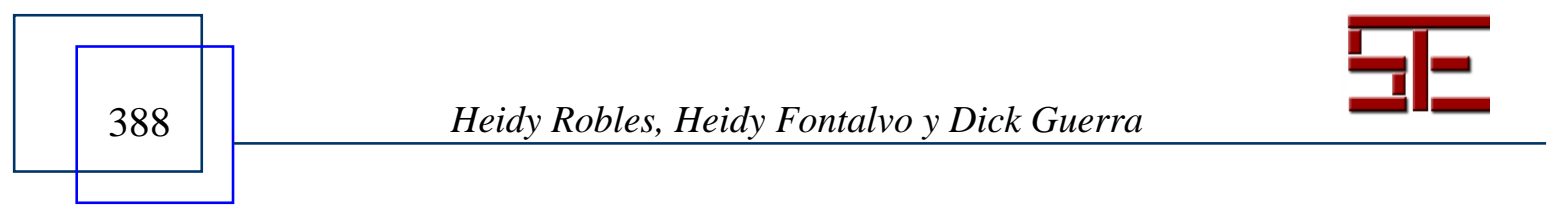




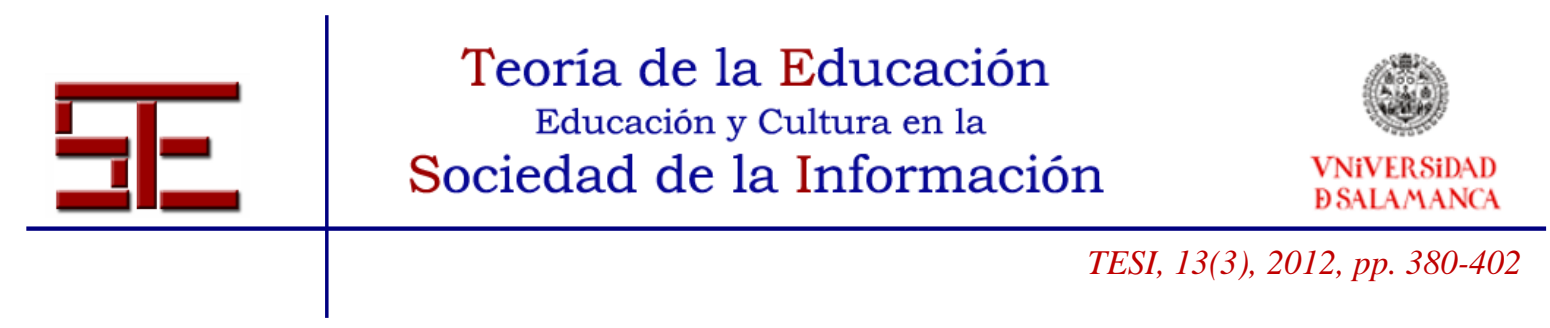

Tabla 1. Diferencias en habilidades escriturales pre y postest

\begin{tabular}{|c|c|c|c|}
\hline & PRETEST & POSTEST & DIFERENCIA \\
\hline Media & 2,7965 & 3,8846 & 1,08 \\
\hline$D T$ & 0,4503 & 0,2931 & 0,285 \\
\hline p-Valor.* (prueba K-S) & 0,847 & 0,683 & 0,59 \\
\hline p-Valor. (prueba $t$ ) & \multicolumn{3}{|c|}{0,000} \\
\hline
\end{tabular}

* Las pruebas estadísticas se analizaron alrededor de un grado de significancia $\alpha=0.1$.

Una vez confirmado que las notas se distribuían normalmente (Prueba K-S, p>0) el análisis estadístico estableció que efectivamente hubo diferencias significativas entre las mediciones del estado inicial y final de las habilidades escriturales luego de la experiencia con el dispositivo móvil $(P=0,00)$. Además, se llevó a cabo un análisis de los resultados en cada uno de los cuatro criterios que se utilizaron en esta investigación para evaluar las habilidades escriturales tanto en el pretest como el postest: Género, Cohesión, Aspectos Gramaticales y Aspectos Mecánicos. La tabla 2 muestra el estado inicial y final de los cuatro criterios. Todas las distribuciones de datos se ajustan a la distribución normal con una probabilidad importante (Prueba K-S, p>0) y los postest superan significativamente los pretest de cada criterio ( $\mathrm{p}$-valor $<0$ ).

Tabla 2. Pretest y postest de criterios género, cohesión, aspectos gramaticales y aspectos mecánicos

\begin{tabular}{|c|c|c|c|c|c|c|c|c|}
\hline & \multicolumn{2}{|c|}{ GÉNERO } & \multicolumn{2}{c|}{ COHESIÓN } & \multicolumn{2}{c|}{$\begin{array}{c}\text { ASPECTOS } \\
\text { GRAMATICALES }\end{array}$} & \multicolumn{2}{c|}{$\begin{array}{c}\text { ASPECTOS } \\
\text { MECÁNICOS }\end{array}$} \\
\hline & Pretest & Postest & Pretest & Postest & Pretest & Postest & Pretest & Postest \\
\hline Media & 3,1346 & 3,4348 & 2,6443 & 3,927 & 2,5178 & 4,091 & 2,889 & 4,086 \\
\hline DT & 0,6485 & 0,6342 & 0,5064 & 0,3451 & 0,576 & 0,3492 & 0,500 & 0,3757 \\
\hline
\end{tabular}

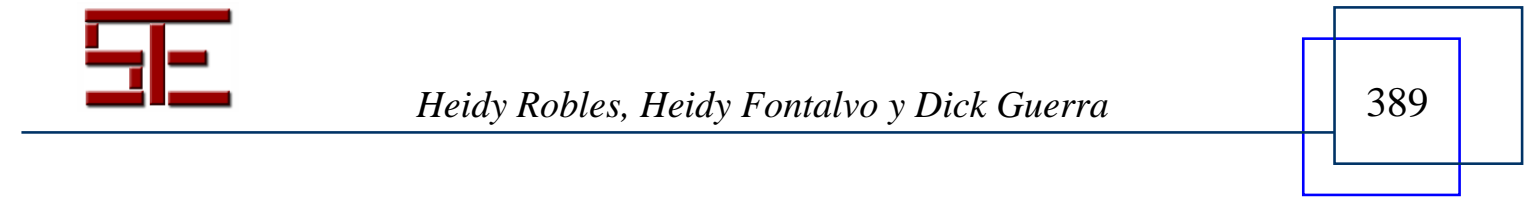




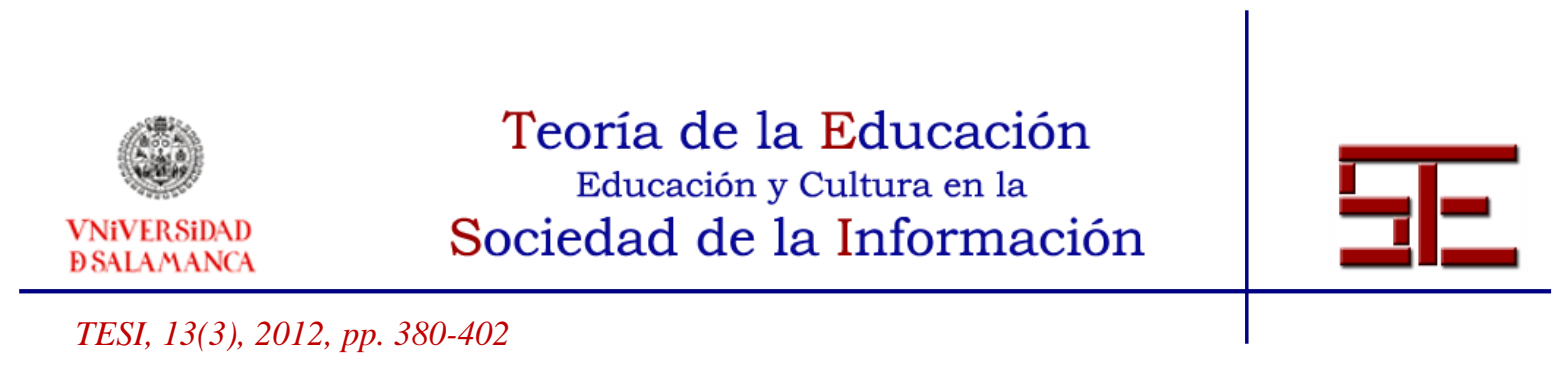

\begin{tabular}{|c|c|c|c|c|c|c|c|c|}
\hline $\begin{array}{c}\mathrm{p}- \\
\text { Valor } \\
\text { (prueba } \\
\mathrm{K}-\mathrm{S})\end{array}$ & 0,993 & 0,982 & 0,94 & 0,697 & 0,884 & 0,785 & 0,946 & 0,96 \\
\hline $\begin{array}{c}\mathrm{p}- \\
\text { Valor } \\
\text { (prueba } \\
t \text { ) }\end{array}$ & 0.000 & 0.000 & 0.000 & 0.000 \\
\hline
\end{tabular}

Seguidamente analizaron los resultados de cada uno de los tipos de texto que componen el criterio Género. En la tabla 3 se observan las diferencias significativas en los pretest y postest de los tipos de textos: recuentos (Sig: 0.00), autobiografías (Sig: 0.00) y cuentos cortos (Sig: 0.04). Sin embargo, en biografías no se presentaron diferencias significativas, al contar con una significancia real mayor que la esperada (Sig: 0.213). Los rendimientos finales en biografías fueron ligeramente inferiores a los iniciales, sin mayor significancia estadística.

Tabla 3. Pretest y postest de cada tipo de texto

\begin{tabular}{|c|c|c|c|c|c|c|c|c|}
\hline $\begin{array}{c}\text { Tipos de } \\
\text { texto } \\
\text { (Género) }\end{array}$ & \multicolumn{2}{|c|}{ RECUENTOS } & \multicolumn{2}{c|}{ BIOGRAFÍAS } & \multicolumn{2}{c|}{ AUTOBIOGRAFÍAS } & \multicolumn{2}{c|}{$\begin{array}{c}\text { CUENTOS } \\
\text { CORTOS }\end{array}$} \\
& Pretest & Postest & Pretest & Postest & Pretest & Postest & Pretest & Postest \\
\hline Media & 3.25 & 3.93 & 3.37 & 3.25 & 2.483 & 3.144 & 3.465 & 3.73 \\
\hline$D T$ & 0.87 & 0.89 & 0.492 & 0.538 & 0.739 & 0.793 & 0.782 & 0.825 \\
\hline $\begin{array}{c}\text { p-Valor } \\
\text { (prueba } \\
\text { K-S) }\end{array}$ & 0.92 & 0.768 & 0.443 & 0.95 & 0.366 & 0.947 & 0.933 & 0.857 \\
\hline $\begin{array}{c}\text { p-Valor } \\
\text { (prueba } t \text { ) }\end{array}$ & \multicolumn{2}{|c|}{0,000} & \multicolumn{2}{c|}{0,213} & \multicolumn{2}{c|}{0,000} & & 0,004 \\
\hline
\end{tabular}

Para efectos de determinar si las diferencias en los rendimientos previos y posteriores de las habilidades escriturales se hallaban en relación con la frecuencia de consulta de los recursos en los dispositivos móviles, se realizó un proceso de correlación estadística simple entre la frecuencia de uso de los mismos y las diferencias en los rendimientos. Como se indica en la Tabla 4, la diferencia en los rendimientos

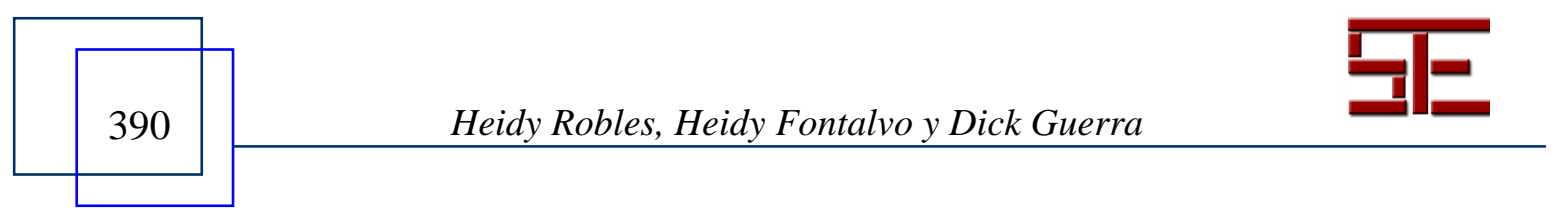




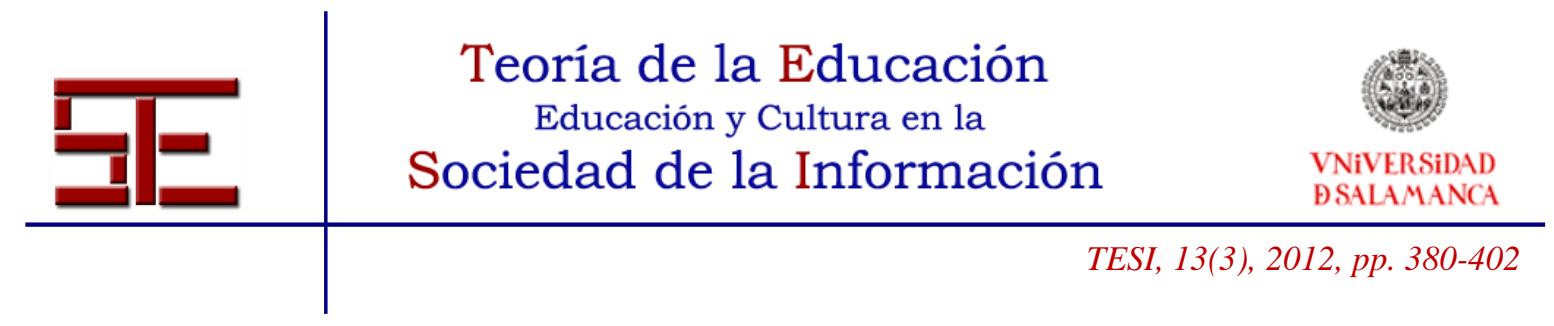

iniciales y finales de las habilidades escriturales se correlacionó significativamente $(\mathrm{r}=0,348 ; \mathrm{P}=0,104)$. De esta manera, los estudiantes que con mayor frecuencia consultaron recursos en el dispositivo móvil fueron los que alcanzaron las mejoras más significativas en sus habilidades escriturales.

Tabla 4. Correlación entre habilidades escriturales y frecuencia de consulta de recursos en dispositivos móviles

\begin{tabular}{|c|c|c|c|}
\hline & DIFERENCIA & PRETEST & POSTEST \\
\hline $\begin{array}{c}\text { Correlación de } \\
\text { Pearson }\end{array}$ & 0,348 & $-0,244$ & $-0,037$ \\
\hline $\begin{array}{c}\text { Sig. (bilateral) - } \\
\text { IC:90\% }\end{array}$ & 0,104 & 0,261 & 0,867 \\
\hline
\end{tabular}

Seguidamente se realizó la correlación de la frecuencia de consulta y las habilidades escriturales de acuerdo a la clasificación de los recursos consultados en los dispositivos: académicos y en inglés ('podcast', multimedia, páginas web, página Web del curso en WebCT, traductores) y varios (no académicos, y en cualquier idioma). Los resultados de la Tabla 5 muestran que hubo correlación estadísticamente significativa $(\mathrm{r}=0.367 ; \mathrm{P}=0.085)$ entre la frecuencia de consulta de los recursos académicos y las diferencias en los rendimientos antes y después de las habilidades escriturales. La correlación entre la diferencia de los rendimientos y la frecuencia de consulta a recursos varios no resultó ser lo suficientemente significativa, $(\mathrm{r}=0.331 ; \mathrm{P}=0.179)$.

Tabla 5. Correlación entre habilidades escriturales y frecuencia de consulta a recursos académicos en inglés y recursos varios

\begin{tabular}{|c|c|c|c|c|}
\hline & & DIFERENCIA & PRETEST & POSTEST \\
\hline \multirow{2}{*}{$\begin{array}{l}\text { Frecuencia uso } \\
\text { RECURSOS } \\
\text { ACADEMICOS } \\
\text { EN INGLES }\end{array}$} & \begin{tabular}{|c} 
Correlación de \\
Pearson
\end{tabular} & 0.367 & -0.346 & -0.179 \\
\hline & $\begin{array}{l}\text { Sig. (bilateral) } \\
\text { - IC: } 90 \%\end{array}$ & 0.085 & 0.106 & 0.415 \\
\hline $\begin{array}{l}\text { Frecuencia uso } \\
\text { de RECURSOS }\end{array}$ & $\begin{array}{c}\text { Correlación de } \\
\text { Pearson }\end{array}$ & ,331 &,- 040 & ,264 \\
\hline
\end{tabular}

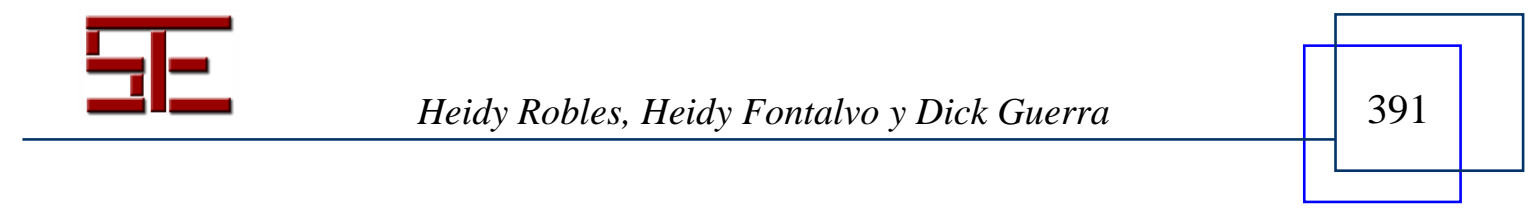




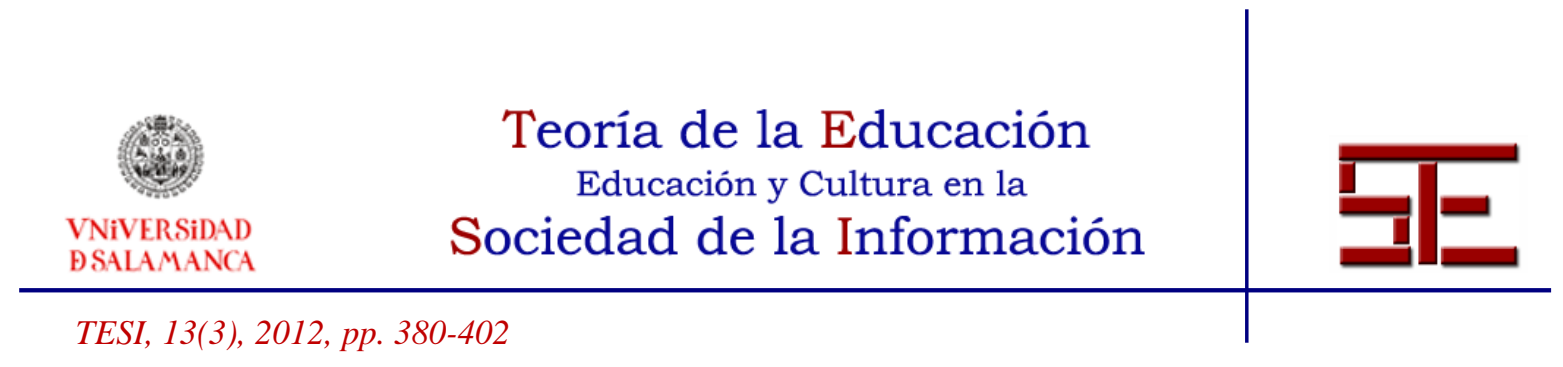

\begin{tabular}{|c|c|c|c|c|}
\hline VARIOS & $\begin{array}{c}\text { Sig. (bilateral) } \\
- \text { IC: } 90 \%\end{array}$ &, 179 &, 875 &, 290 \\
\hline
\end{tabular}

Los resultados indican correlaciones inversas entre el criterio Cohesión y la frecuencia de uso de todos los recursos académicos en inglés $(\mathrm{r}=-0.41 ; \mathrm{P}=0.052)$ y específicamente de los 'podcast' diseñados por el docente $(r=-0.37 ; p=0.082)$. También se encontró una correlación inversa entre los aspectos mecánicos y la frecuencia de uso de páginas web, traductores, multimedia, página web del curso en WebCT en el dispositivo móvil ( $\mathrm{r}=-0409 ; \mathrm{p}=0.053$ ). La correlación negativa indica una relación inversa entre las variables, según la cual los estudiantes con más deficientes resultados en estos aspectos fueron los que con mayor frecuencia consultaron esos tipos de recursos.

\subsection{Caracterización y frecuencia de consulta de los recursos}

Los recursos consultados en los dispositivos móviles fueron caracterizados como académicos en inglés y varios. Los recursos académicos en inglés fueron 'podcast' diseñados por el profesor, la página web del curso en WebCT, traductores, páginas Web, y multimedia. En la categoría varios se incluyeron aquellos que no se relacionaban con el contenido académico y que no eran en ingles. En la Gráfica 1 se observa que los estudiantes consultaron con mayor frecuencia los recursos académicos en inglés (58\%), sin embargo, los materiales no académicos (otros) también fueron consultados frecuentemente $(48 \%)$.

Gráfica 1. Recursos consultados a través del dispositivo móvil
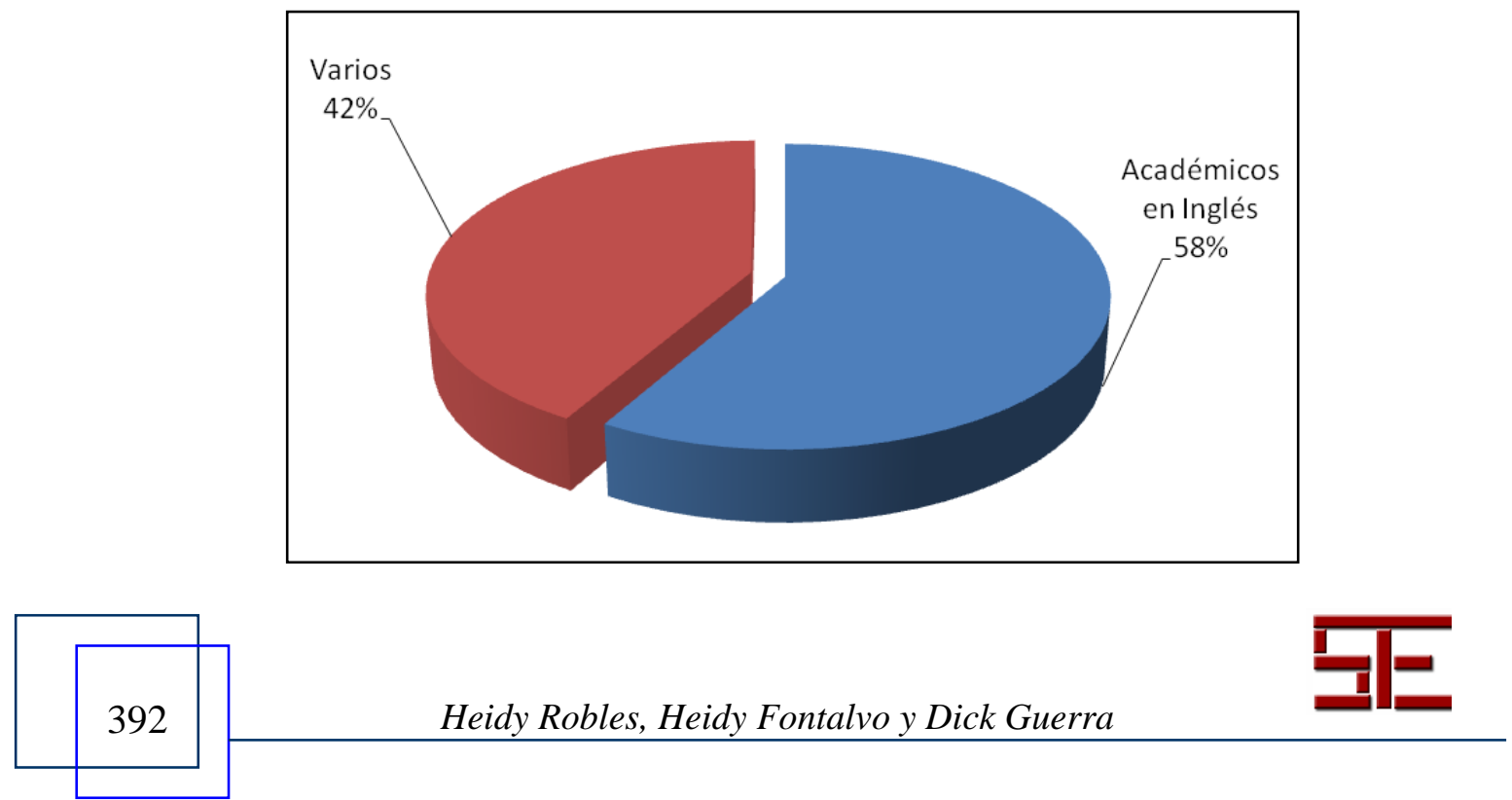


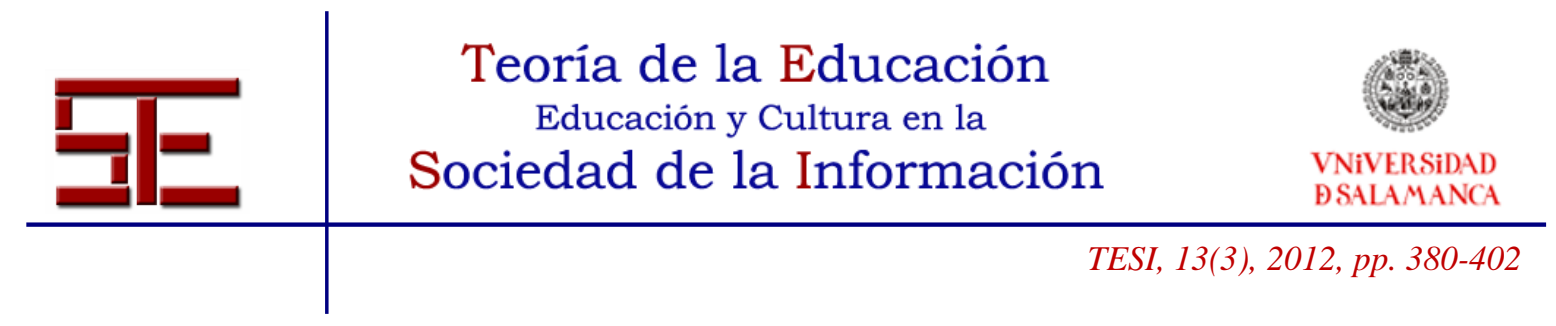

En la Gráfica 2 se observa la frecuencia de consulta de los recursos académicos y en inglés. Los recursos que los estudiantes consultaban con mayor frecuencia fueron los 'podcast' diseñados por el docente (64\%) la pagina web del curso en WebCT $(16 \%)$, otras páginas web $(12 \%)$, traductores $(6 \%)$ y multimedia $(2 \%)$.

Gráfica 2. Frecuencia consulta recursos académicos y en inglés

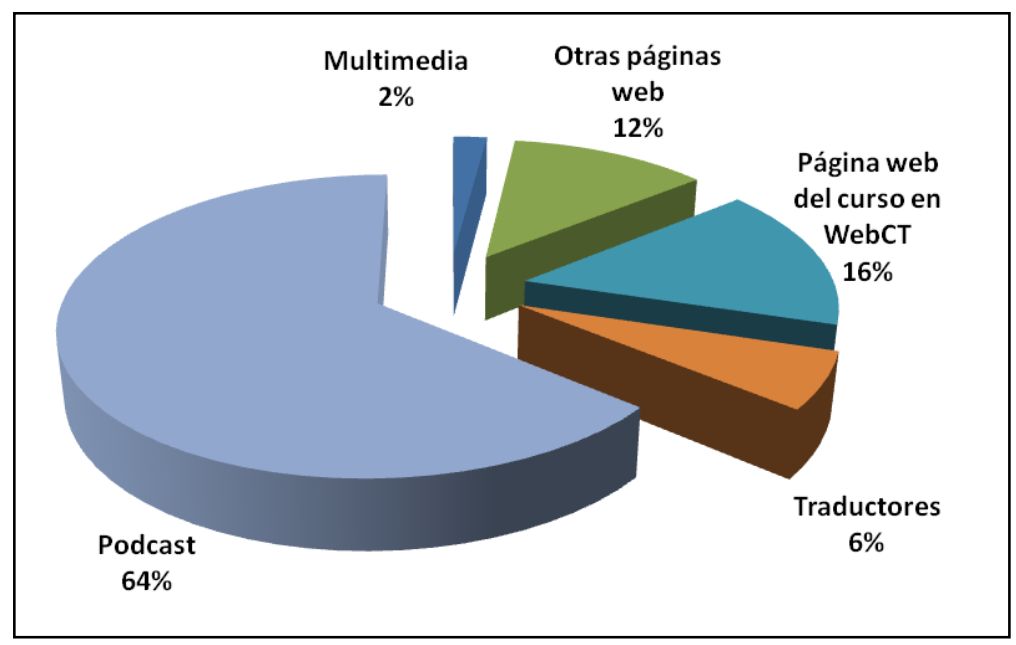

Por otra parte, en la Gráfica 3 se observa que los recursos varios más consultados fueron herramientas sociales $(28 \%)$, entre las cuales se encuentran redes sociales $(18 \%)$ y wikis $(10 \%)$; páginas web (23\%), y las páginas web de otros cursos en la LMS (22\%). El dispositivo móvil fue también usado, el $8 \%$ de las veces para leer noticias y en otras oportunidades para ver videos (6\%), revisar el correo electrónico (6\%), descargar imágenes (4\%) y, en menor medida, para escuchar música (1\%) y descargar aplicaciones (1\%).

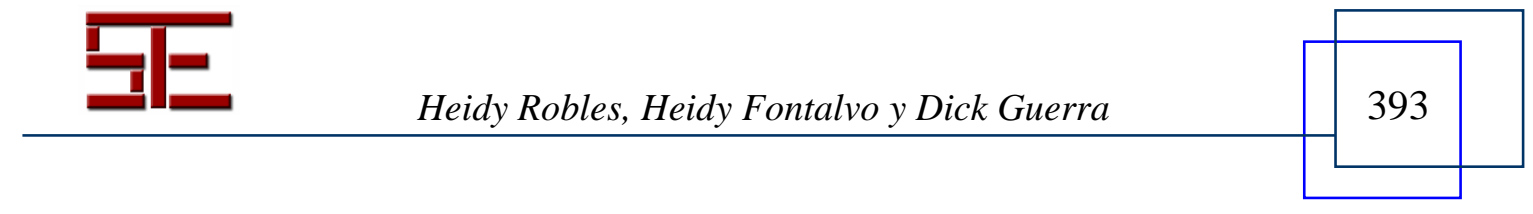




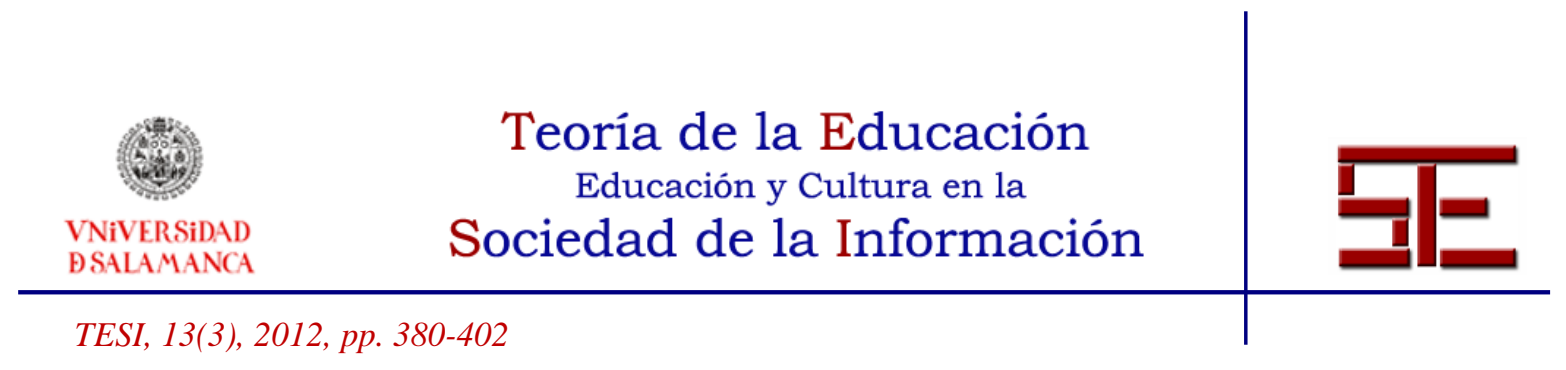

Grafica 3. Frecuencia de consulta de recursos varios

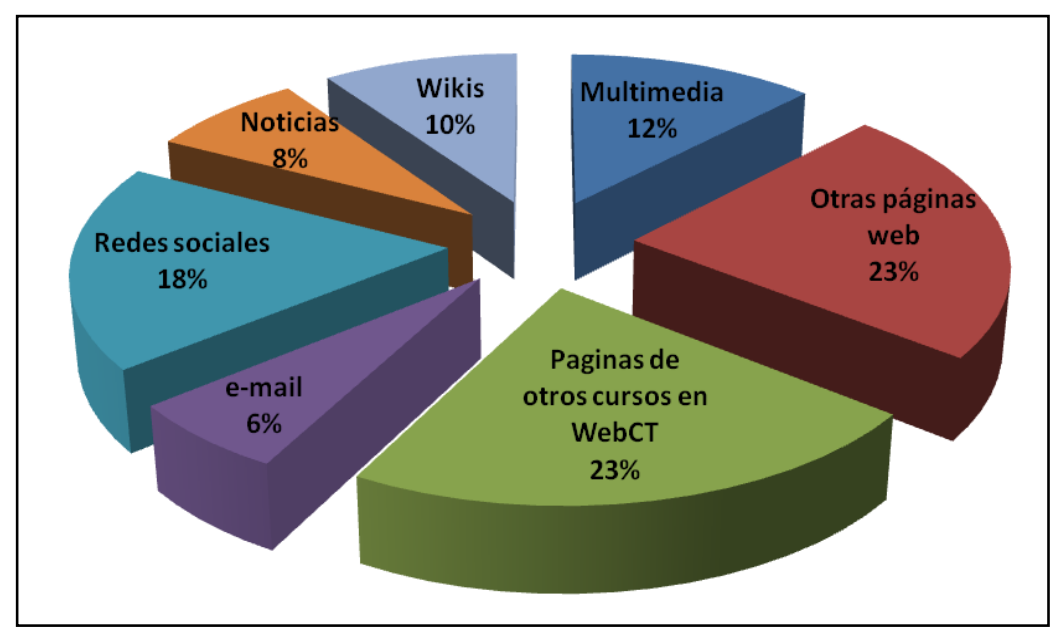

\subsection{Percepción de los estudiantes}

Se realizó una encuesta con el fin de conocer diversos aspectos de la experiencia de uso de los dispositivos móviles en el contexto académico. En términos generales los estudiantes mencionaron que los 'i Pods' fueron dispositivos móviles fáciles de usar $(100 \%)$ y transportar (94\%). En cuanto a los recursos académicos los estudiantes manifestaron que los consultaban en los dispositivos móviles mientras se dirigían a otros lugares $(60 \%)$, pero en gran medida fueron consultados en sus computadores personales $(87 \%)$. El acceso a los recursos complementó su proceso de aprendizaje (80\%), mejoró su comprensión de los temas (93\%) y apoyaron el desarrollo de sus habilidades escriturales $(80 \%)$. Desde su perspectiva, los 'podcast' diseñados por el profesor fueron pertinentes al género narrativo y buen recurso de apoyo (100\%). La mayoría $(73 \%)$ no habían usado algún dispositivo móvil para aprender y todos coincidieron en que a futuro lo harían. La Gráfica 4 resume el porcentaje de contribución que los participantes adjudicaron a cada uno de los recursos académicos consultados en la producción de cada tipo de texto. Los resultados indican en la producción del tipo de texto Recuentos todos los recursos contribuyeron en un porcentaje similar menos los traductores $(0 \%)$. En cuanto a la producción de Autobiografías, los recursos contribuyeron en igual medida y en menor medida los traductores (13\%) y la pagina web del curso en WebCT (7\%). Con respecto a

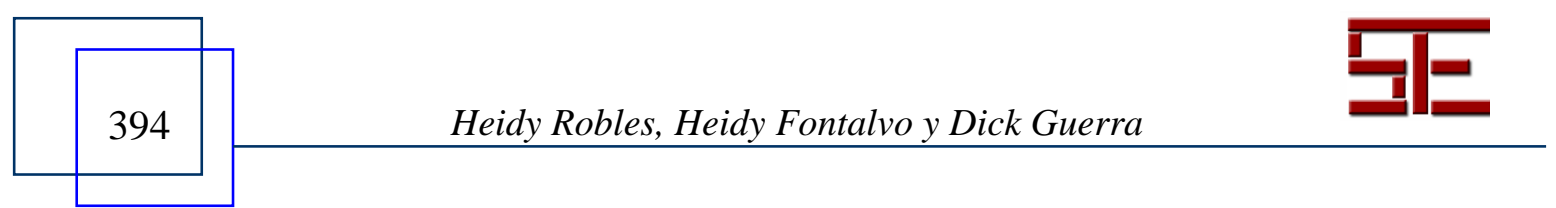




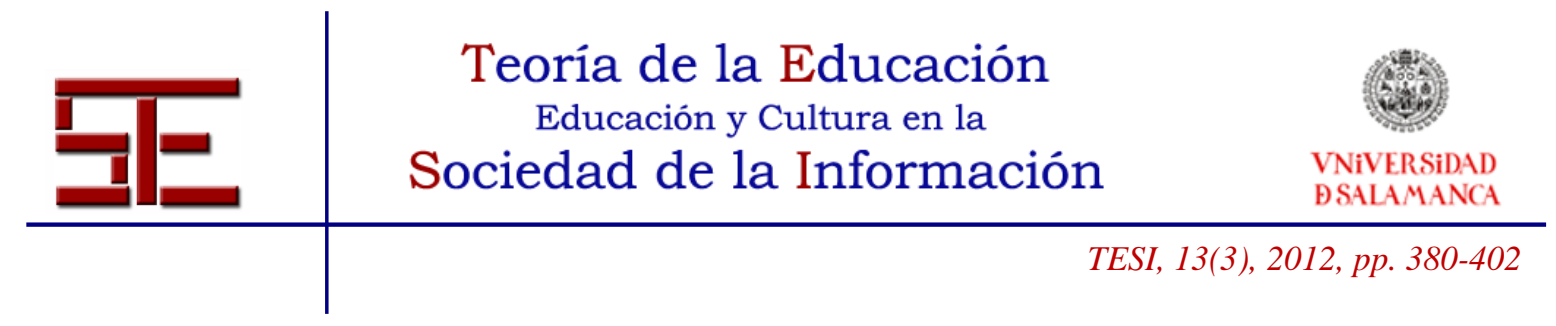

Biografías los recursos que más contribuyeron fueron las páginas web en inglés (40\%) y la página web del curso en WebCT (33\%) y los traductores (7\%). Finalmente, en la producción de Cuentos cortos los traductores y diccionarios 'online' como 'Google Translator' y 'Wordreference' fueron los recursos que más contribuyeron (80\%) y de menor contribución fueron las páginas Web en inglés (13\%).

Gráfica 4. Contribución de recursos académicos a la producción de textos

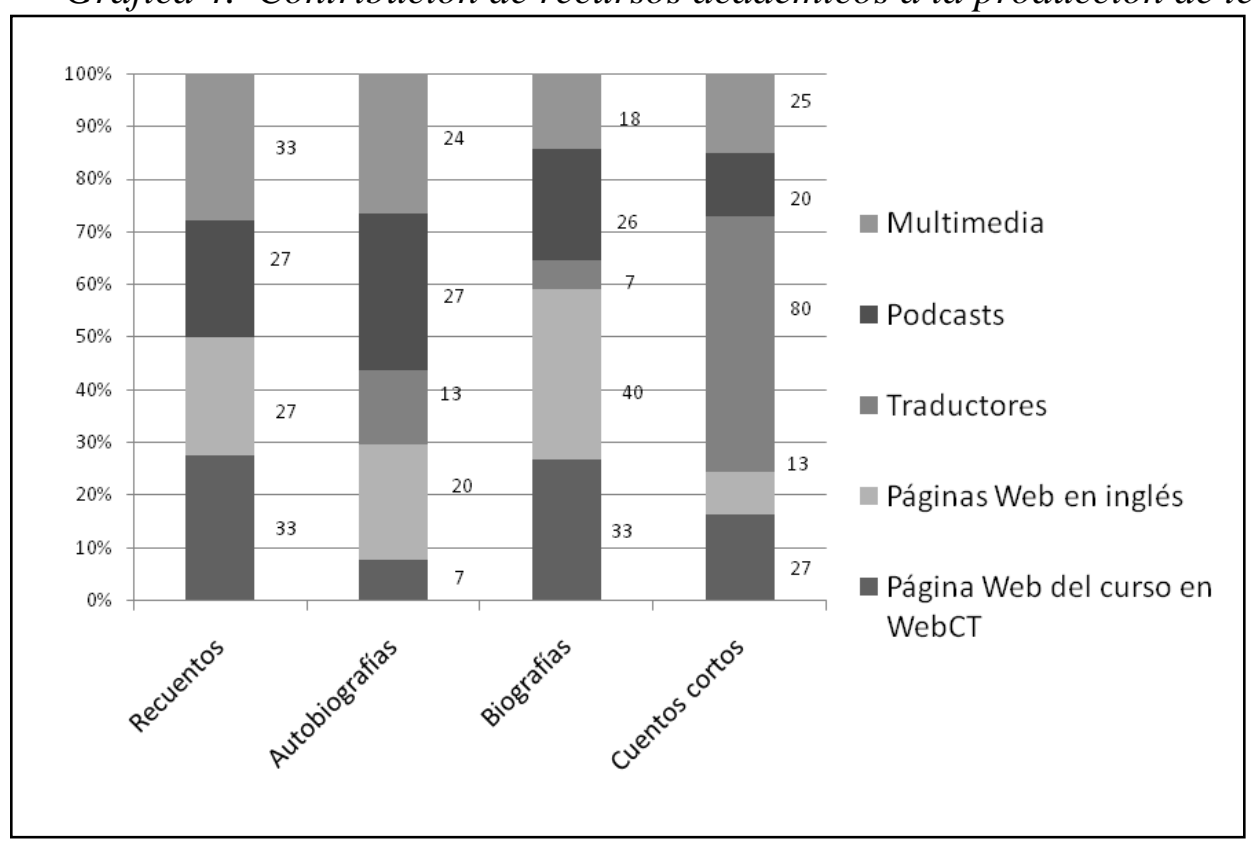

\section{DISCUSIÓN Y CONCLUSIONES}

Los resultados del estudio muestran que el acceso a recursos en dispositivos móviles puede significativamente ayudar al estudiante en la mejor producción de textos y sobre todo aquellos que por su estructura requieren conocimientos previos, vocabulario, gramática y que su construcción es de carácter personal. Se observa que existen diferencias significativas después de consultar los recursos en todos los criterios que se seleccionaron para evaluar los textos escritos: enfoque de género, cohesión, aspectos gramaticales y aspectos mecánicos. Esto concuerda con los hallazgos de Martínez y Tabuenca (2009) y Chaisiri (2010). Asimismo se encuentran mejoras en la producción de recuentos, autobiografías y cuentos cortos, a excepción de biografías.

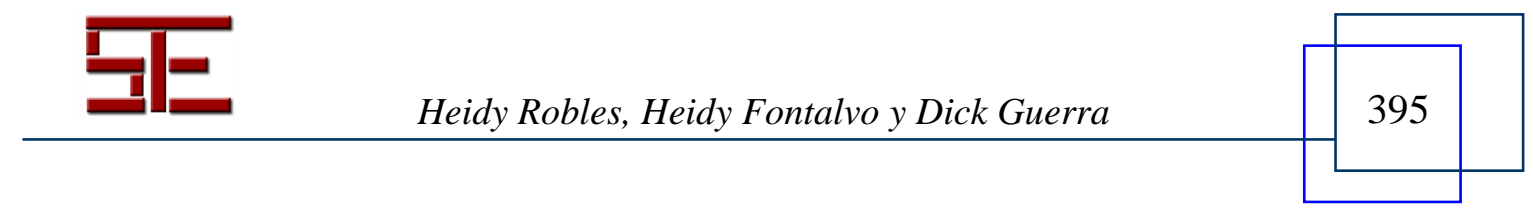




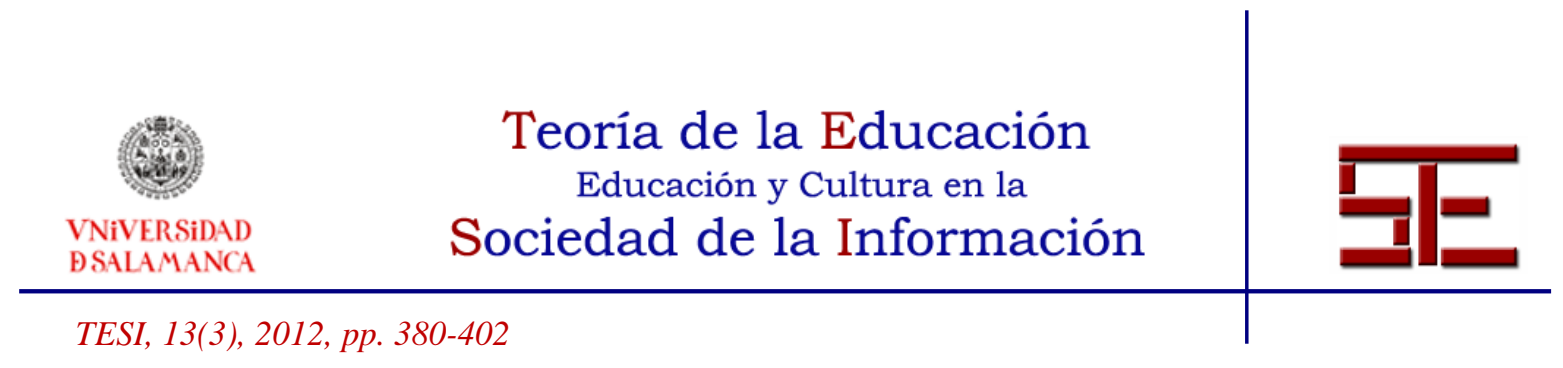

Las diferencias significativas en la producción del tipo de texto recuento pueden deberse a que el estudiante escribe sobre eventos que le han sucedido, así como en autobiografía en donde escribe cronológicamente sobre eventos personales. Por su parte, en cuentos cortos cada estudiante narró un cuento que le fue asignado por el profesor. En el tema de biografías, donde no se reportaron diferencias significativas, el estudiante requería realizar una pre-lectura de material adicional en relación con la vida y obras del personaje que servía de apoyo al desarrollo a la redacción de la misma. Probablemente, el requisito de leer material externo se haya convertido en un elemento que pudo dificultar el desarrollo espontáneo de los estudiantes cuando producen este tipo de texto, al igual que la longitud del mismo. A propósito de esto, Hidi y Anderson (citados por Kirkland \& Saunders, 1991) sostienen que una de las limitaciones frecuentes que presentan los estudiantes a la hora de sintetizar es la naturaleza del material; es decir, la longitud del texto y la complejidad de los mismos. Si la revisión de dichos recursos halló correlación con el avance de la mayoría los tipos de texto y no en biografías, es precisamente porque escribir este tipo de texto requiere además de la base conceptual (de saber qué es una biografía) un saber práctico, que se desarrolla con la repetición de la acción y la progresiva automatización del conjunto de pasos.

Además, los datos indican una relación entre la frecuencia de uso de los recursos en el dispositivo móvil y la mejora en habilidades escriturales. Se encuentran correlaciones significativas entre la frecuencia de uso de los recursos académicos y en inglés mas no los recursos no académicos (varios). En este sentido, los estudiantes que más consultaron recursos académicos en ingles tuvieron un mejor rendimiento en sus habilidades escriturales. Es de esperarse que la consulta de recursos académicos en inglés contribuyera a una mejoría en los escritos, puesto que en este tipo de recursos existe una exposición constante al idioma y a elementos como la estructura de tipos de texto del género narrativo, ejemplos de los mismos, reglas de ortografía, uso de mayúsculas, consulta inmediata del significado de palabras, oraciones y párrafos, en ocasiones precisos como los diccionarios en línea y en otra aproximados como es el caso de los traductores. Los recursos académicos proporcionaron elementos del género que eran requeridos para lograr textos que además de cumplir con la norma sugerida para su estructura, fueron coherentes, cohesivos y además gramaticalmente correctos.

Un aspecto que vale la pena analizar fue que los estudiantes expresaron en la encuesta que en ocasiones no usaron los dispositivos móviles para acceder a los recursos académicos sino que preferían utilizar sus computadores personales, a los

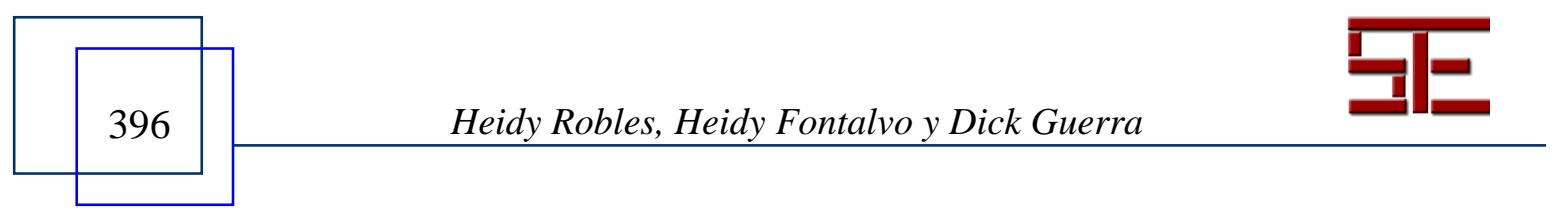




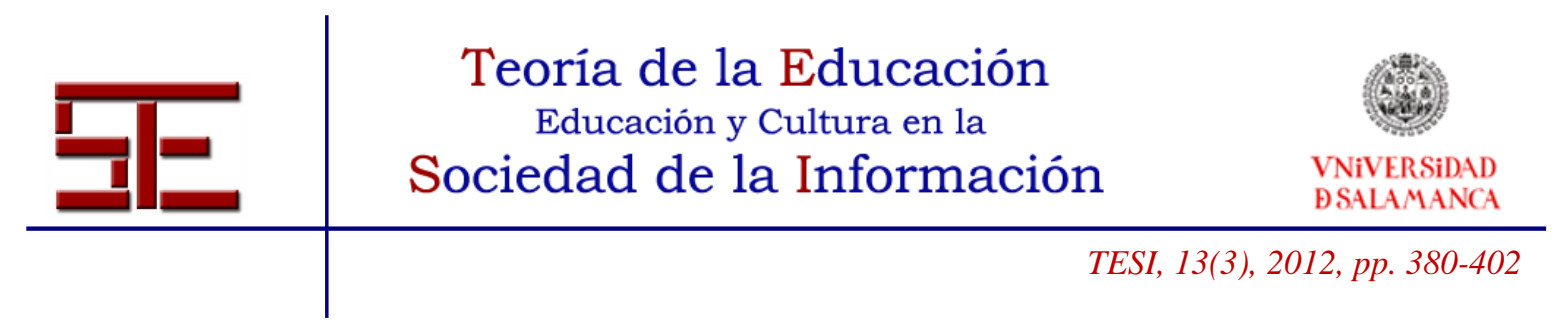

cuales no se tuvo acceso para obtener el registro de la frecuencia de consulta, pues no era objeto de este estudio. Esta preferencia concuerda con lo encontrado en otros estudios (Stockwell, 2010; Copley, 2007; Middleton, 2009; Ducate \& Lomicka, 2009) donde se halló que los estudiantes preferían revisar actividades y recursos como 'podcast' en sus computadores y no con tanta frecuencia en sus dispositivos móviles; esto sugiere que las aplicaciones y usos de recursos en ' $m$-learning' no deben verse como un reemplazo sino como un complemento al proceso personal de aprendizaje. Aunque la preferencia de consulta siga siendo en el computador personal, se confirma que existe ganancia en el aprendizaje al contar también con la opción del dispositivo móvil confirmando los resultados de Sandberg, Maris \& De Geus (2011) y De Jong, Specht \& Koper (2010).

En conclusión, los dispositivos móviles brindan a los aprendices la posibilidad de mantenerse en contacto con recursos tanto académicos como de ocio, que pueden ser integrados a una sesión de estudio organizada, o bien hacer parte del estudio independiente un momento casual, de un tiempo libre, de un rato muerto. No obstante, es menester de quienes piensan incorporar tecnología móvil al contexto de la enseñanza-aprendizaje de las lenguas requerir de cautela, en cierto sentido, porque el uso de dispositivos móviles debe ser estimado como un medio de apoyo para el desarrollo de habilidades no como un reemplazo. Contar con un enfoque como el de género ayuda al mejoramiento de producciones escritas pues el estudiante está familiarizado con el tipo de producto que debe producir. Asi mismo, la consulta espontánea que realizan los aprendices a diferentes recursos académicos disponibles en la web podría estar significando una ayuda latente en cuanto a la coherencia, cohesión $\mathrm{y}$ aspectos gramaticales de sus escritos.

Finalmente, se recomienda examinar posteriormente cuáles otras dinámicas del aprendizaje mediado por dispositivo móvil se ajustan para el desarrollo de habilidades escriturales en una segunda lengua, qué tipos de contenidos son los más apropiados y la manera como los estudiantes integran los dispositivos móviles a su rutina de estudio.

\section{BIBLOGRAFÍA}

Brown, H. (2007). Teaching by principles an interactive approach to language pedagogy. New York: Pearson- Longman.

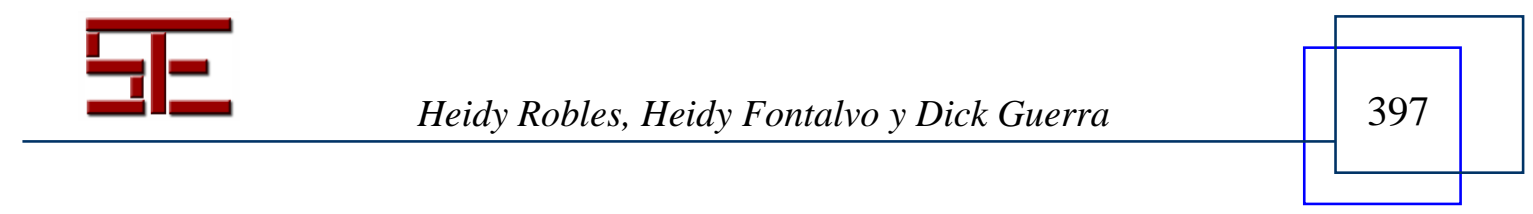




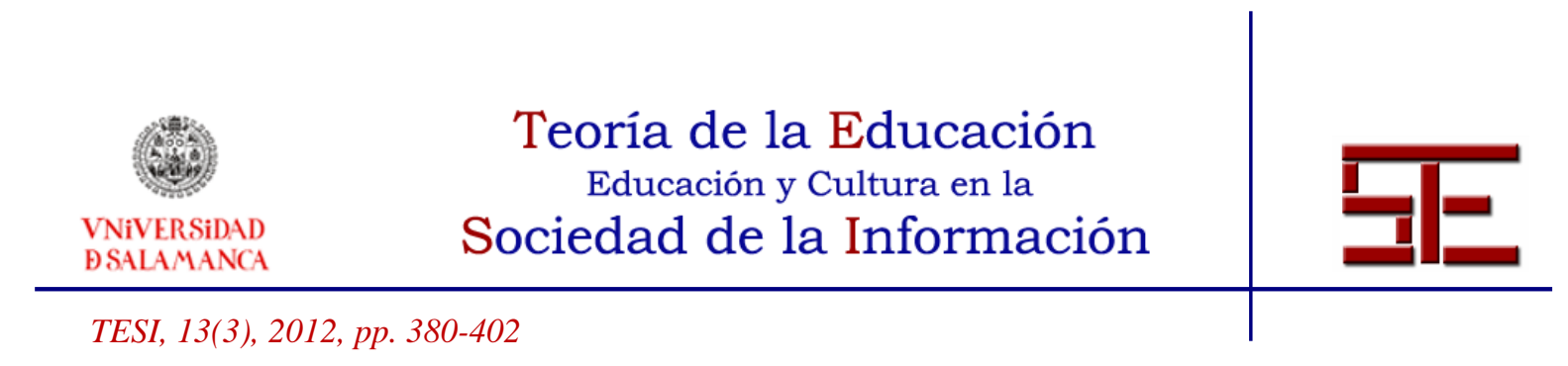

Cavus, N. \& Ibrahim, D. (2009). M-Learning: an experiment in using SMS to support learning new English language words. British Journal of Educational Technology, 40, 1, 78-91.

Chaisiri, T. (2010). An investigation of the teaching of writing with a specific focus on the concept of genre. International Journal of Learning, 17, 2, 195-206.

- (2010). Implementing a genre pedagogy to the teaching of writing in a university context in Thailand. Language Education in Asia, 1, 181-199.

Chen, N., Hsieh, S. \& Kinshuk. (2008). Effects of short-term memory and content representation type on mobile language learning. Language Learning \& Technology, 12, 3, 93-113.

Chinnery, G. M. (2006). Going to the MALL: Mobile Assisted Language Learning. Language Learning \& Technology, 10, 1, 9-16.

Copley, J. (2007). Audio and video podcast of lectures for campus-based students: production and evaluation of student use. Innovations in Education and Teaching International, 44, 4, 387-399.

Cushing, S. (2002). Assessing writing. New York: Cambridge University Press.

De Jong, T., Specht, M. \& Koper, R. (2010). A study of contextualized mobile information delivery of language learning. Educational Technology \& Society, $13,3,110-125$.

Díaz, A. (2009). Aproximación al texto escrito. Ed. Medellín: Universidad de Antioquia.

Díaz, F. \& Hernández, G. (2002). Estrategias docentes para un aprendizaje significativo. Una interpretación constructivista. Ed. México: McGrawHill Latinoamericana.

Ducate, L. \& Lomicka, L. (2009). Podcasting: an effective tool for honing language students' pronunciation? Language Learning and Technology, 13, 3, 66-86.

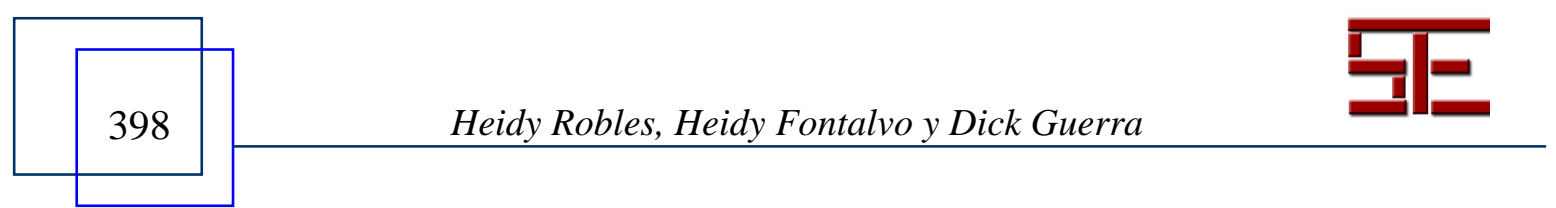




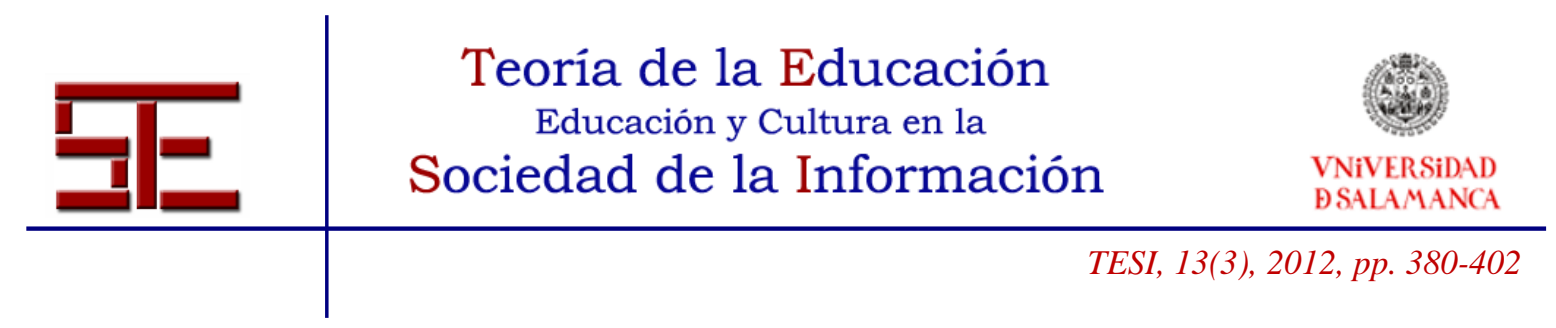

Gromik, N. (2008). EFL learner use of podcasting resources: a pilot study. The JALT CALL Journal, 4, 2, 47-60.

Hanson-Smith, E. (2000). Hands-on teacher training: presentation software. En E. Hanson-Smith. (Ed.), Technology-enhanced learning environments (137148). Alexandria, VA: TESOL.

Jarvis, C. \& Dickie, J. (2010). Podcasts in support of experiential field learning. Journal of Geography in Higher Education, 34, 2, 173-186.

Kiernan, P. \& Aizawa, K. (2004). Cell phones in task based learning: Are cell phones useful language learning tools? ReCALL, 16, 1, 71-84.

Kirkland, M. R. \& Saunders, M.A.P. (1991). Maximizing student performance in summary writing: Managing the cognitive load. Tesol Quaterly, 25, 1, 105121.

Lomicka, L. \& Lord, G. (2011). Podcasting - Past, Present and Future: Applications of Academic Podcasting In and Out of the Language Classroom. En B. R. Facer \& M. Abdous. (Eds.), Academic Podcasting and Mobile Assisted Language Learning: Applications and Outcomes (1-20). Hershey, PA: IGI Global

Looi, C., Seow, P., Zhang, B., So, H., Chen, W. \& Wong, L. (2010). Leveraging mobile technology for sustainable seamless learning: a research agenda. British Journal of Educational Technology, 41, 2, 154-169.

Lu, M. (2008). Effectiveness of vocabulary learning via mobile phone. Journal of Computer Assisted Learning, 24, 515-525.

Martin, J. \& Rose, D. (2007). Working with discourse: meaning beyond the clause. Great Britain: Athenaeum Press.

Martínez, M. \& Tabuenca, M. (2008). Integrating CALL and Genre Theory: A proposal to increase students' literacy. ReCALL 20,1, 67-81.

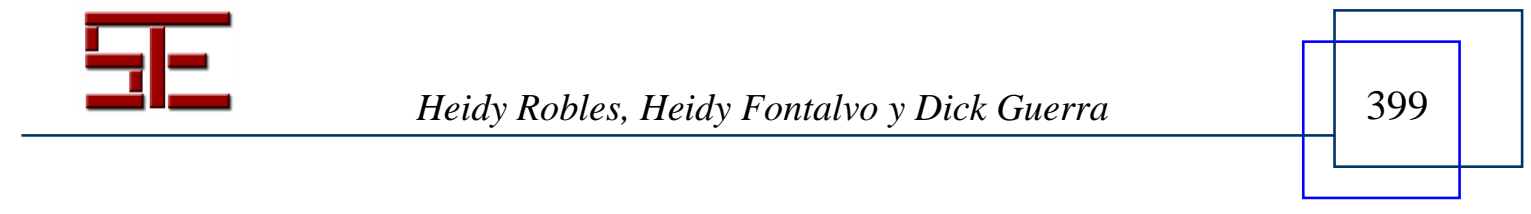




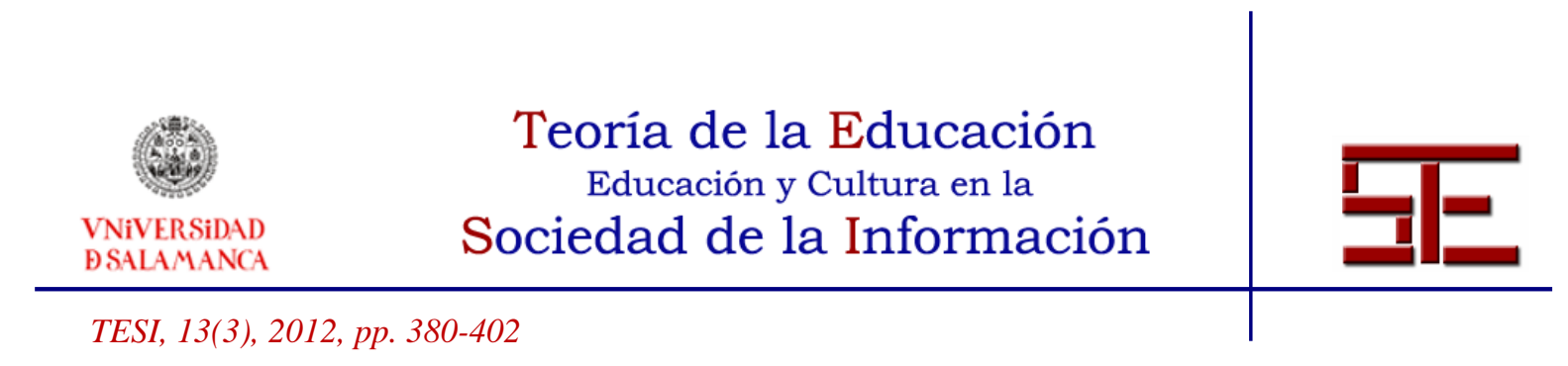

Middleton, A. (2009). Beyond podcasting: creative approaches to designing educational audio. ALT-J, Research in LearningTechnology. 17, 2, 143-155.

Mork, C. (2009). Using Twitter in EFL education. JALT CALL Journal, 5, 3, 41-56.

Nunan, D. (1999). Second language teaching and learning. Boston. Heinle \& Heinle publicaciones.

Parson, V., Reddy, P., Wood, J. \& Senior, C. (2009). Educating an iPod generation: undergraduate attitudes, experiences and understanding of vodcast and podcast use. Learning, Media and Technology, 34, 3, 215-228.

Richards, J. \& Renandya, W. (2002). Methodology in language teaching.An anthology of current practice. New York: Cambridge University Press.

Rose, D. (2008). Reading to learn: accelerating learning and closing the gap. Australia: s. 1.

Sandberg, J., Maris, M. \& De Geus, K. (2011). Mobile English learning: an evidencebased study with fifth graders. Computers \& Education, 57, 1334-1347

Shih, J., Chuang, C. \& Hwang, G. (2010). An inquiry-based mobile learning approach to enhancing social science learning effectiveness. Educational Technology \& Society, 13, 4, 50-62.

Stockwell, G. (2007). A review of technology choice for teaching language skills in the CALL literature. ReCALL, 19, 2, 105-120.

- (2010). Using mobile phones for vocabulary activities: examining the effect of the platform. Language Learning and Technology, 14, 2, 95-110.

Taylor, J. (2007). Learning on the fly. Choose the right tools to deliver learning content to employees anytime, anywhere. HR Technology Magazine, September, 127-131.

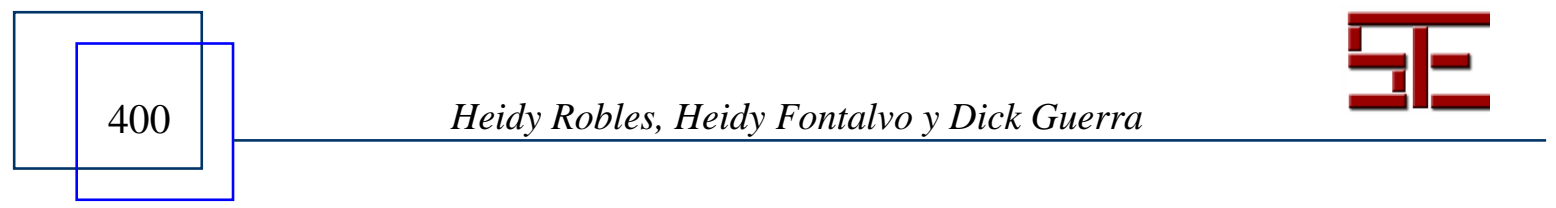




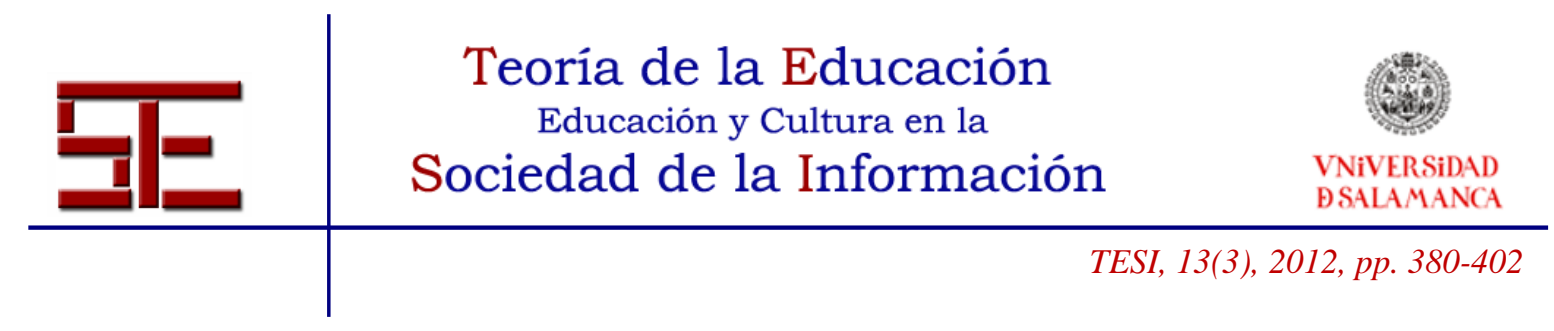

Vallance, M. \& Shibata, Y. (2008). Effective implementation of interactive podcasting for the Web 2.0 generation. JALT CALL Journal, 4, 1, 60-74.

Zheng, Y. (1999). Providing students with effective feedback in the writing process. Teaching English in China, 43, 3, 18-26.

\section{ANEXO 1. RÚBRICA DE HABILIDADES ESCRITURALES}

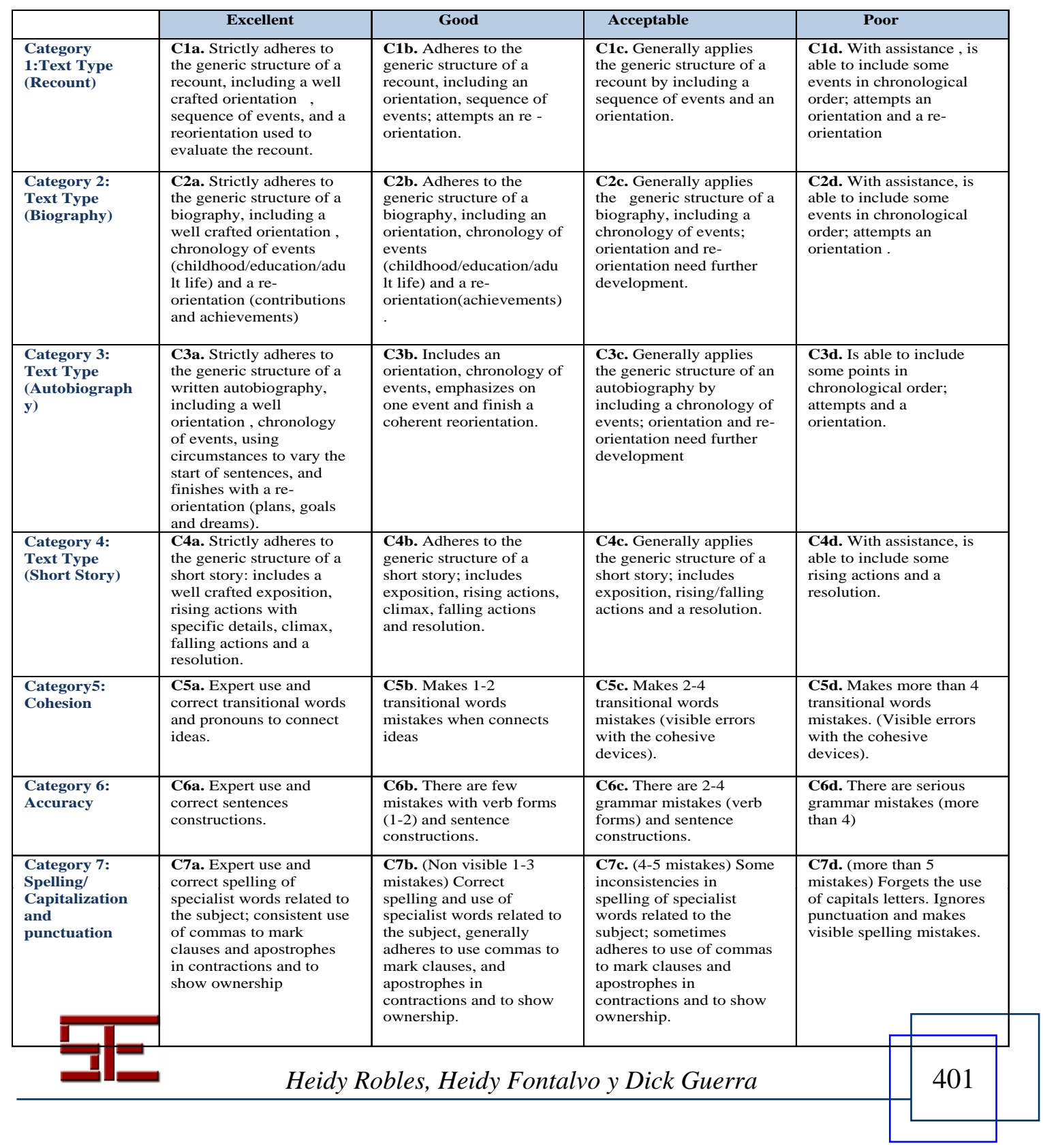




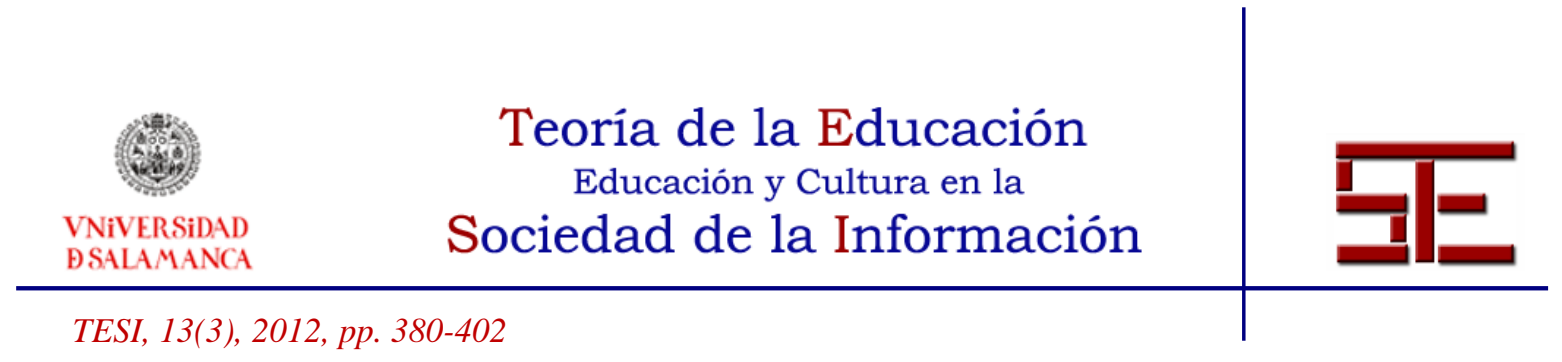

Para citar el presente artículo puede utilizar la siguiente referencia:

Robles, H., Fontalvo, H. y Guerra, D. (2012). Desarrollo de habilidades escriturales apoyado con tecnología móvil. Revista Teoría de la Educación: Educación y Cultura en la Sociedad de la Información. 13(3), 380-401 [Fecha de consulta: dd/mm/aaaa].

http://campus.usal.es/ revistas_trabajo/index.php/revistatesi/article/view/9221/9481 